\title{
Activation of HERV-K Env protein is essential for tumorigenesis and metastasis of breast cancer cells
}

\author{
Fuling Zhou ${ }^{1,2, *}$, Ming Li ${ }^{1, *}$, Yongchang Wei ${ }^{1,3, *}$, Kevin Lin ${ }^{4}$, Yue Lu ${ }^{4}$, Jianjun Shen ${ }^{4}$, \\ Gary L. Johanning ${ }^{1}$, Feng Wang-Johanning ${ }^{1}$ \\ ${ }^{1}$ Viral Oncology Program, Center for Cancer and Metabolism, SRI International, Menlo Park, California, USA \\ ${ }^{2}$ Department of Clinical Hematology, Zhongnan Hospital, Wuhan University, Wuhan, Hubei, China \\ ${ }^{3}$ Department of Radiation and Medical Oncology, Zhongnan Hospital, Wuhan University, Wuhan, Hubei, China \\ ${ }^{4}$ Department of Epigenetics and Molecular Carcinogenesis, Science Park, The University of Texas MD Anderson Cancer \\ Center, Smithville, Texas, USA \\ *Co-first authors
}

Correspondence to: Feng Wang-Johanning, email: feng.wang-johanning@SRI.com

Keywords: HERV-K, breast cancer, shRNA, Ras signaling, tumorigenesis and metastasis

Received: April 22, 2016

Accepted: August 11, 2016

Published: August 20, 2016

\section{ABSTRACT}

Human endogenous retrovirus type K (HERV-K) Env protein was previously demonstrated to be overexpressed in human breast cancer (BC) cells and tissues. However, the molecular pathways driving the specific alterations are unknown. We now show that knockdown of its expression with an shRNA (shRNAenv) blocked BC cell proliferation, migration, and invasion. shRNAenv transduction also attenuated the ability of BC cells to form tumors, and notably prevented metastasis. Mechanistically, downregulation of HERV-K blocked expression of tumor-associated genes that included Ras, p-RSK, and p-ERK. The major upstream regulators influenced by HERV-K knockdown were p53, TGF- $\beta 1$, and MYC. Of interest, when the HERV-K env gene was overexpressed in shRNAenv-transduced BC cells using an HERV-K env expression vector, Ras/Raf/MEK/ERK pathway signaling was restored. CDK5, which alters p53 phosphorylation in some cancers, was upregulated and p53 was downregulated when HERV-K was overexpressed. CDK5 is also a mediator of TGF- $\beta 1$-induced epithelialmesenchymal transition and migration in cancer cells, and is involved in tumor formation. Importantly, reductions in migration, invasion, and transformation of BC cells stably transduced with shRNAenv was reversed after adding back a vector with a synonymous mutation of HERV-K env. Taken together, these results indicate that HERV-K Env protein plays an important role in tumorigenesis and metastasis of BC.

\section{INTRODUCTION}

Early detection, diagnosis, and treatment of solid tumors that include breast cancer (BC), and particularly metastatic $\mathrm{BC}$, is still a challenge today. The existence of previously unrecognized causative agents of $\mathrm{BC}$ may be one reason why a cure for $\mathrm{BC}$ has been so elusive. Furthermore, treatment of patients with $\mathrm{BC}$ or other cancers has been challenging due to the heterogeneity of the disease and the absence of well-defined molecular targets. One promising etiological factor in $\mathrm{BC}$ may be the involvement of an endogenous retrovirus (ERV).

ERV sequences make up $>8 \%$ of the human genome [1] and some may show retroviral activity in humans that include tumor induction. Our laboratory showed that the human endogenous retrovirus type $\mathrm{K}$ (HERV-K) family, which is usually silenced, commonly becomes induced and activated in BC cells and tissues [2-7]. We confirmed overexpression of HERV-K in $\mathrm{BC}$ patients, and the expression significantly increased with disease stage, grade, p53 mutation and lymph node metastasis [6]. There was also significantly increased expression of HERV-K mRNA in sera of BC patients whose cancer had metastasized three years after baseline blood draws, compared with $\mathrm{BC}$ patients whose cancer did not metastasize, irrespective of baseline receptor status [4]. Importantly, we did not detect expression of HERV-K in a wide panel of normal human tissues 
$[8,9]$. In further support of a role of HERV-K in metastatic cancers, we observed that HERV-K specific T cells were cytotoxic $[5,10]$, and HERV-K antibody had anti-tumor effects [6].

In this study we examined whether tumor-promoting activity of the HERV-K Env protein in BC cell lines was mediated by the Ras/Raf/MEK/ERK signaling pathway both in vitro and in vivo.

\section{RESULTS}

\section{Reduced expression of HERV-K env RNA or protein in cell lines transduced with an shRNA targeting HERV-K env}

The overexpression of HERV-K in various breast cancer cell lines has been demonstrated previously $[5,6,8]$. Higher percentages of HERV-K Env protein expression were demonstrated in $\mathrm{BC}$ cell lines (Hs578T, MDA-MB-231, MCF-7, MDA-IBC-3, and BT549) than in HEK293 or HEK293T cells by flow cytometry (FACS), cell enzyme-linked immunosorbent assay (ELISA), immunofluorescence staining (IFS), immunohistochemistry (IHC), and immunoblot (data not shown). siRNA has been used to inhibit the expression of specific messenger RNAs to produce gene silencing effects for cancer therapeutics[11]. Six siRNAs targeting HERV-K env were designed and were found to knock down HERV-K expression in $3 \mathrm{BC}$ cell lines (Figure S1A). Furthermore, several siRNAs inhibited MDA-MB-231 $\mathrm{BC}$ cell proliferation (Figure S1B), and when either 6 or 12 siRNAs were combined, there was very strong and significant inhibition of HERV-K expression in T47D, SKBR3, and MDA-MB-231 BC cells (Figure S1C). Since shRNA has a lower rate of degradation and turnover relative to siRNA, siRNA 670 was selected and used for synthesis of shRNA (shRNAenv). A scrambled siRNA 670 was used to synthesize shRNAc.

Transduction with an shRNA targeting HERV-K using a pGreenPuro (System Biosciences, Palo Alto, CA) expression vector (shRNAenv; Figure S2A and S2B) [8], relative to transduction with a scrambled control (shRNAc), led to significantly reduced expression of RNA in MCF-7 ( $p=0.0007$; Figure 1A), Hs578T $(p=0.0065$; Figure 1B), MDA-MB-231 $(p=0.0004$; Figure 1C), SKBR3 ( $p=0.0055$; Figure 1D), and MDAMB-435.eB1 ( $p=0.0009$; Figure 1E) cells, as assessed by qRT-PCR using primers described previously [3]. shRNAenv treatment led to reduced expression of HERV-K type 1 in most of the BC cells we tested, and of type 2 in Hs578T and SKBR3 cells, by RT-PCR using primers described previously [2]. Reduced expression of HERV-K Env protein was also detected in the above cell lines by immunoblot (Figure 1A-1E) using the previously described anti-HERV-K monoclonal antibody $6 \mathrm{H} 5[5,12]$.

\section{Inhibition of cell proliferation, colony formation and cell transformation in shRNAenv transduced cancer cells}

Cell number counts or a proliferation assay [6] showed significantly reduced cell proliferation of MDAMB-231, MDA-MB-435.eB1, MCF-7, and Hs578T cells on days 3-4, except for SKBR3 cells, which showed decreased proliferation on days 6-8 after shRNA knockdown of HERV-K (Figure 2A). An anchorage-independent growth assay revealed significantly reduced colony formation in MCF-7 ( $p<0.0001$; Figure 2B), Hs578T $(p<0.0001$; Figure 2C), MDA-MB-231 $(p<0.0001$ or $p=0.0034$; Figure 2D), SKBR3 ( $p=0.0039$, Figure S2C), and MDAMB-435.eB1 ( $p=0.0046$; Figure S2D) cells, after shRNA knockdown of HERV-K. In addition, cell migration, as determined by a scratch assay, was decreased in MDAMB-231, SKBR3, and MDA-MB-435.eB1 cells transduced with shRNAenv (data not shown). Transwell plate assays also showed reduced migration of MDA-MB-435.eB1 and SKBR3 cells, and reduced invasion of MDA-MB-435.eB1 cells after shRNAenv knockdown of HERV-K (Figure S2E).

\section{Reduced tumor formation and metastasis to lung in vivo}

Significantly reduced tumor growth was observed in mouse xenografts of MDA-MB-231 (Figure 3A), MDAMB-435.eB1 (Figure 3B), and SKBR3 (Figure 3C) cells transduced with shRNAenv compared with shRNAc. Furthermore, tumor sizes and weights were significantly reduced in mouse xenografts bearing MDA-MB-231 $(p=0.0005$; Figure 3A), MDA-MB-435.eB1 $(p<0.0001$; Figure 3B) and SKBR3 $(p=0.0205$ and $p<0.0001$; Figure $3 \mathrm{C}$ ) cell lines transduced with shRNAenv. Reduced tumor weight was also observed in SKBR3 cells transduced with an shRNA targeting HERV-K gag (shRNAgag; $p=0.0001$; Figure $3 \mathrm{C}$ ), but not as much as in cells transduced with shRNAenv ( $p=0.0037)$. Importantly, significantly reduced metastasis to lung (lower green fluorescence in tissue pieces) was demonstrated in mice bearing MDA-MB-231 shRNAenv xenografts compared with those bearing MDA-MB-231 shRNAc xenografts $(p=0.0393$; Figure 3D). HERV-K env RNA expression was significantly downregulated in xenograft tumors of shRNAenv compared with shRNAc MDA-MB-231 ( $p=0.0449$ or $p=0.0004$; Figure S3A) and MDAMB-435.eB1 ( $p=0.0006$; Figure S3B) cells by qRT-PCR. These data indicate that reduced tumor sizes may be due to downregulated expression of HERV-K by shRNA.

\section{Phenotypic changes of $B C$ cells after downregulated expression of HERV-K env RNA}

We observed that long-term culture of $\mathrm{BC}$ cells transduced with shRNAenv led to slower cell growth 
rates, which was accompanied by phenotypic changes in MCF-7 cells at day 45 post-transduction (Figure 4A), and in Hs578T at day 60 post-transduction (Figure 4B). The cells transduced with shRNAenv showed a spindle-like elongated phenotype, compared to cells transduced with shRNAc. However, no significant change in phenotype was noted in MDA-MB-231 cells transduced with shRNAenv after similar numbers of days post-transduction (day 30 to day 80; Figure 4C). An image of cells cultured under anchorage-independent growth conditions from the $3 \mathrm{BC}$ cell lines transduced with shRNAenv or shRNAc is shown in Figure 4D. Significantly reduced numbers of colonies and smaller colony sizes were observed in the $3 \mathrm{BC}$ cell lines transduced with shRNAenv compared with shRNAc cells.

Cell cycle analysis revealed $\mathrm{S}$ phase arrest in $\mathrm{MCF}-7$, Hs578T, and MDA-MB-231cell lines transduced with shRNAenv (Figure 4E), compared to these cells transduced with shRNAc or parent cells (parent cell data not shown). Downregulated expression of HERV-K env gene caused a significant increase of cells in the $\mathrm{S}$ phase of all three $\mathrm{BC}$ cell lines and decrease in $\mathrm{G} 1$ in two triple negative $\mathrm{BC}(\mathrm{TNBC})$ cell lines (Hs578T and MDA-MB-231). There was a corresponding significant decrease of cells in
A

MCF-7

qRT-PCR:

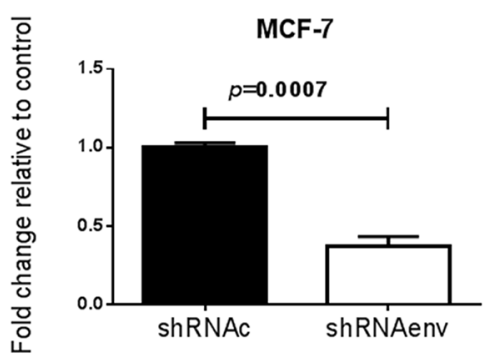

B

Hs578T

qRT-PCR:

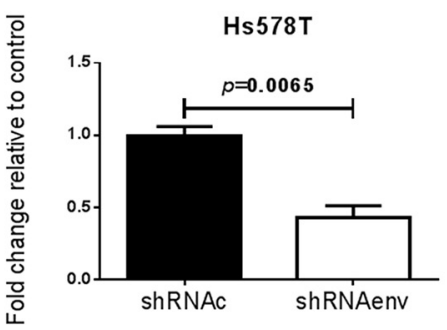

C

qRT-PCR:

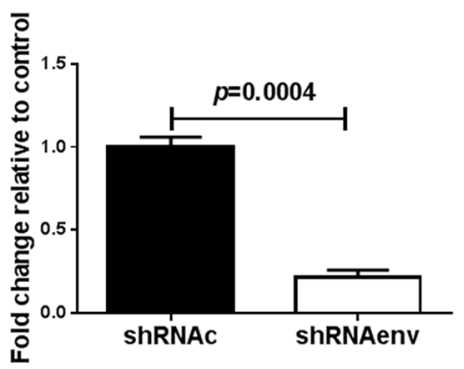

MDA-MB-231

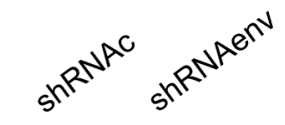

RT-PCR:

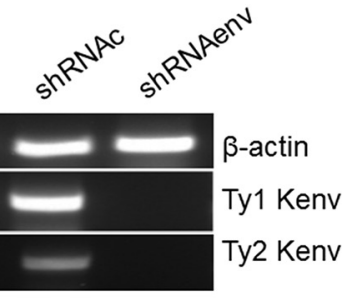

ACTB

Immunoblot:

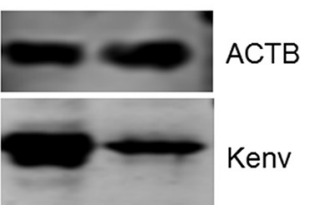

RT-PCR: $\beta$-actin Ty1 Kenv Ty2 Kenv ACTB

Kenv

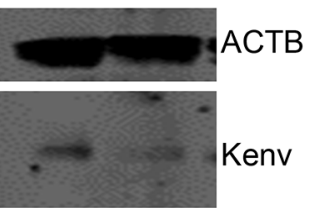



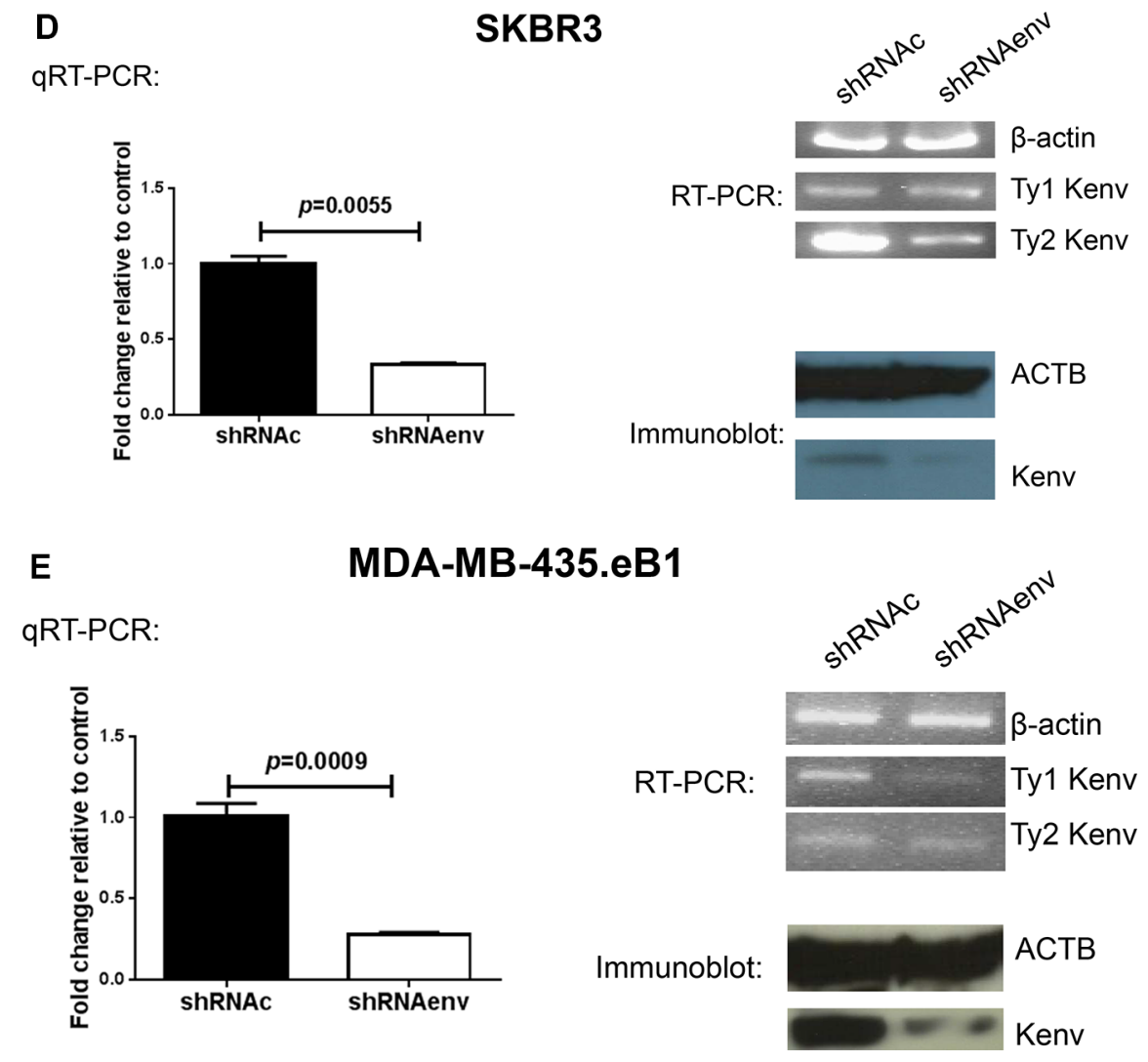

Figure 1: Expression of HERV-K in BC cell lines transduced with shRNAenv vs. shRNAc. Quantitative RT-PCR, RT-PCR, and immunoblot using HERV-K specific primers and anti-HERV-K antibody were used to determine whether HERV-K knockdown blocked its expression. Changes in HERV-K expression in shRNAenv relative to controls (shRNAc) were observed by qRT-PCR assays in MCF-7 (A), Hs578T (B), MDAMB-231 (C), SKBR3 (D), and MDA-MB-435.eB1 (E) cells. The deviation (error bars) represents standard error of the mean (SEM), and the statistical test performed was unpaired $t$ test $(n=3)$. Downregulated expression of HERV-K env RNA (type 1) in MCF-7, Hs578T, MDAMB-231, MDA-MB-435.eB1, or type 2 in Hs578T and SKBR3 (type 2 only) cells was demonstrated by RT-PCR. There are two types of HERV-K: type 1 has a 292 bp deletion near the $5^{\prime}$ end of the env gene, whereas type 2 does not have this deletion. RTPCR is employed to detect the two types of HERV-K env, using primers specific for type 1 or type 2. Downregulated expression of HERV-K Env protein was demonstrated by immunoblot in cell lines transduced with shRNAenv, using an anti-HERV-K monoclonal antibody (6H5). ACTB antibody was used as control.

the G2-M phases in MCF-7, and a slight but nonsignificant increase of cells in G2-M phases in Hs578T and MDAMB-231 cells. The percentages of cells in various phases are shown in Figure S3C.

\section{RNA-seq analysis}

Knockdown of HERV-K resulted in dramatic decreases in $\mathrm{BC}$ cell proliferation in vitro and tumor growth in vivo, and greatly decreased metastasis to the lung. To address mechanisms underlying HERV-K effects on cell proliferation and metastasis, RNA-Seq was employed to evaluate gene expression in shRNAenv cells compared with shRNAc cells. We then input genes differentially expressed between the shRNAenv and shRNAc, along with their expression levels, into the Ingenuity Pathway Analysis (IPA) program to identify functional networks and signaling pathways that are affected by HERV-K env downregulation. Several signaling pathways were identified that had statistically significant $P$ values, and multiple biological processes were affected. A summary of Upstream Regulator and Disease or Functions Annotation from these cell lines is shown in Table 1 and Table 2, respectively.

After IPA, the Canonical Pathways predicted with statistical significance after HERV-K knockdown are shown in Figure S4A for the BC cell lines (MDA-MB-231, MCF-7, and SKBR3) and in Figure S4B for the tumor biopsies (MDA-MB-435.eB1 and SKBR3). Signaling networks of MDA-MB-231 and MCF-7 cell lines show a major downregulation of EGFR and NF-kB (Figure S4C). Overexpression of EGFR has been demonstrated in approximately half of cases of triple-negative breast cancer and inflammatory breast cancer. EGFR and its downstream pathway regulate epithelial-mesenchymal transition (EMT), migration, and tumor invasion [13]. NF-kB plays a key role in regulating the immune response to infection and promotes breast cancer tumor-initiating cells 


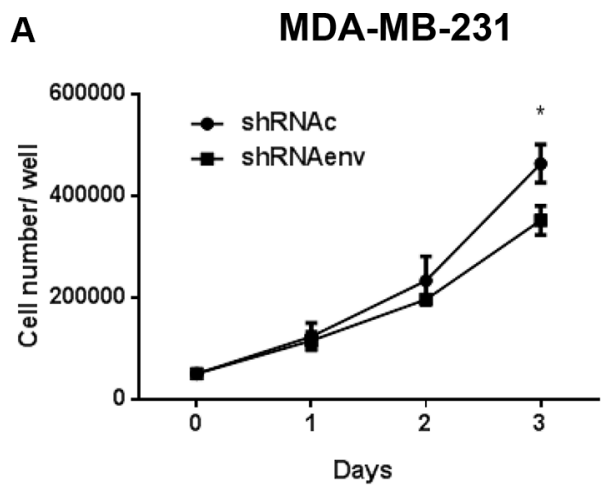

SKBR3

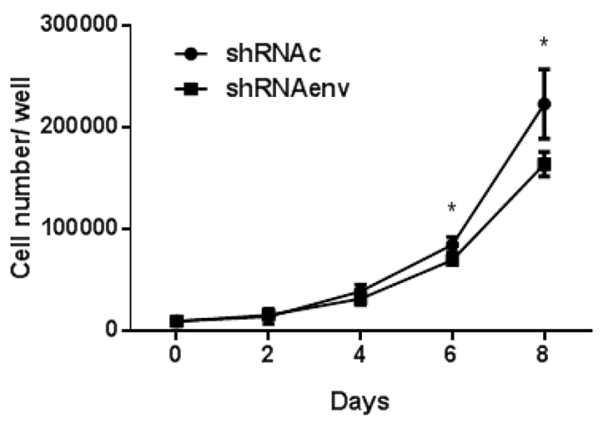

\section{MCF-7}

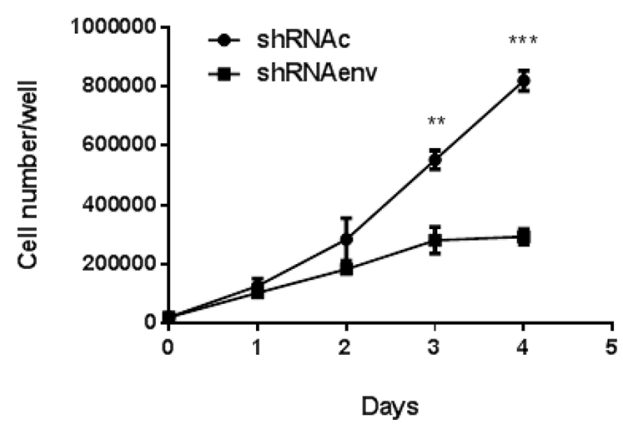

B

$4 X$

shRNAenv

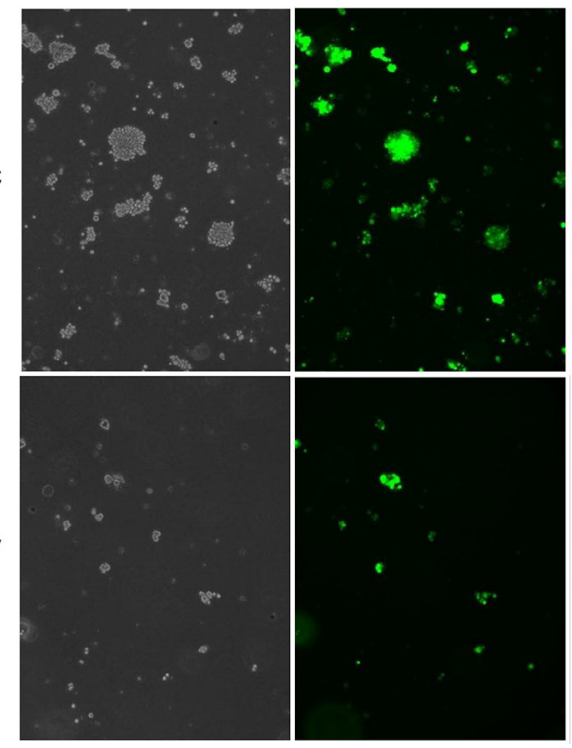

MDA-MB-435. eB1

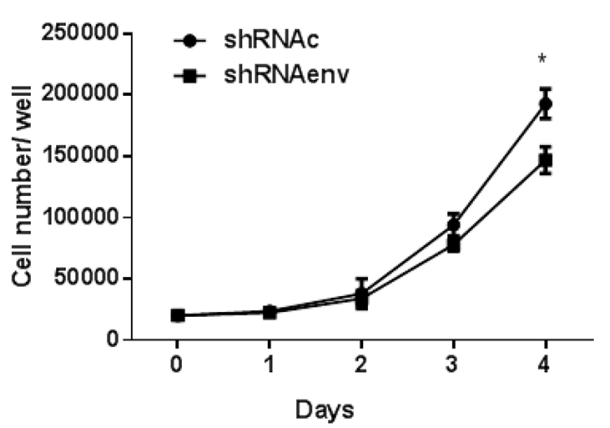

Hs578T

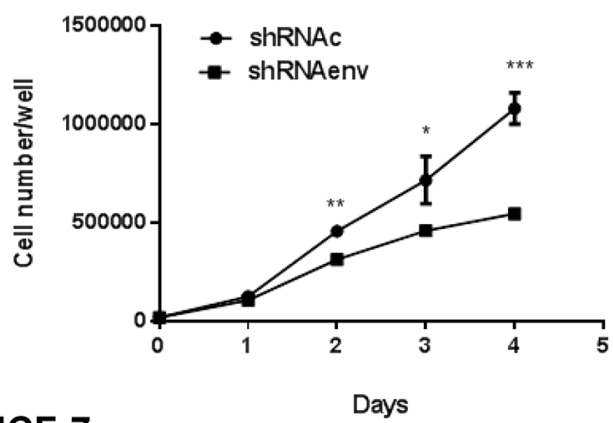

Days

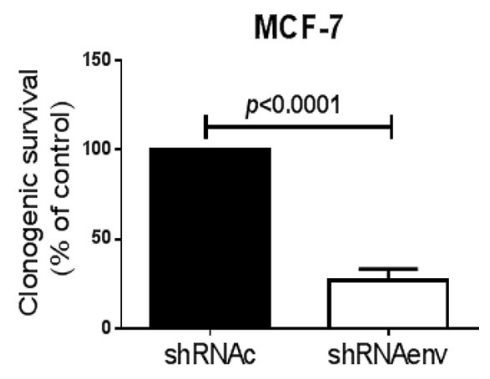



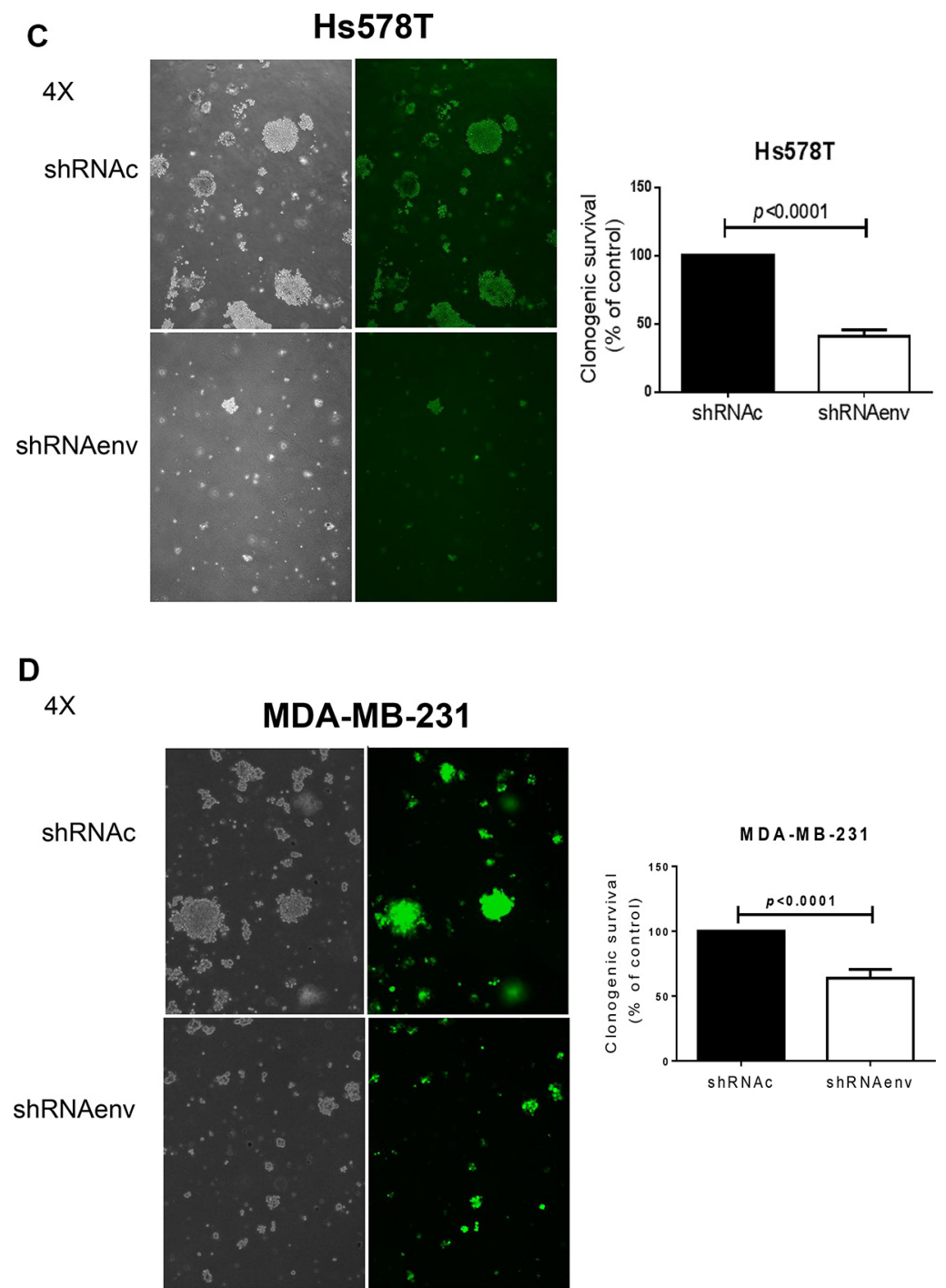

Figure 2: Effect of HERV-K knockdown on cell growth and anchorage-independent growth of BC cells. (A) Significantly reduced cell proliferation, assessed by counting live cell numbers, was observed for MDAMB-231, MDA-MB-435.eB1, SKBR3, Hs578T, and MCF-7 cells ( $n=3$; unpaired $t$ test), after HERV-K knockdown by shRNAenv. An anchorage-independent growth assay was used to determine cell transformation after transduction with shRNAenv and shRNAc $(n=9$; unpaired $t$ test). Reduced colony numbers were demonstrated for MCF-7 (B) $(p<0.0001 ; 10$ days post-seeding), Hs578T (C) $(p<0.0001 ; 10$ days post-seeding), MDA-MB-231 (D) ( $p<0.0001 ; 10$ days post-seeding and $p=0.0034 ; 2$ weeks post-seeding).

[14]. Signaling networks of SKBR3 and MDA-MB-435. eB1 cell lines (Figure S4D) show a major convergence on ERK1/2 after HERV-K knockdown, while the network from SKBR3 (tumor biopsies or cell lysis; Figure S4E), showed a centering on MYC. Both the ERK1/2 and MYC networks play key roles in cancer development.

IPA revealed that, for the $4 \mathrm{BC}$ cell lines evaluated, the transcriptional regulators $\mathrm{p} 53$ and MYC were the major upstream regulators influenced by HERV-K knockdown (Table 1). Transforming growth factor, $\beta 1$ (TGFB1) was by far the most common growth factor upstream regulator in all $4 \mathrm{BC}$ cell lines that was impacted by HERV-K knockdown. $\beta$-estradiol was the major endogenous chemical, and dexamethasone the major drug, affected by HERV-K knockdown. The major cytokine controlling changes in gene expression after HERV-K knockdown was TNF, the major kinase was ERBB2, and the major oncogene was HRAS and/or KRAS. Other significant upstream pathway changes associated with HERV-K env knockdown were ERK, ESR1, and MEK.

IPA disease and functional endpoints identified several categories of disease and cell function affected by shRNA knockdown of HERV-K. In the Cellular Growth and Proliferation category, proliferation of cells was the main endpoint affected. Endpoints affected by knockdown in the Cell Death and Survival category included cell death, apoptosis, and necrosis. In the Cancer category, cancer, epithelial neoplasia, and metastasis were the 
endpoints influenced by HERV-K knockdown, and in the Cellular Movement category, cell movement and invasion of tumor cell lines were the major endpoints affected by HERV-K knockdown (Table 2).

\section{Phosphorylation profiles of kinases in HERV-K knockdown cells}

Cellular extracts prepared from the MCF-7 cell line transduced with shRNAenv vs. shRNAc were compared using phosphoprotein arrays. The top ten upregulated proteins in MCF-7 cells transduced with shRNAenv compared with shRNAc were p38a, MSK1/2, Fgr, HSP27, TOR, EGFR, AMPK $\alpha 1$, Akt1/2/3 S473, STAT3 Y705 and STAT2, and the top ten downregulated proteins were eNOS, RSK1/2/3, HSP60, SAR5a/b, Fyn, Lck, Lyn, p70 S6 Kinase, Hck, and Akt1/2/3 T308. The phosphorylation profiles of kinases and their protein substrates in MCF-7 cells transduced with shRNAenv vs. shRNAc are shown in Table 3.
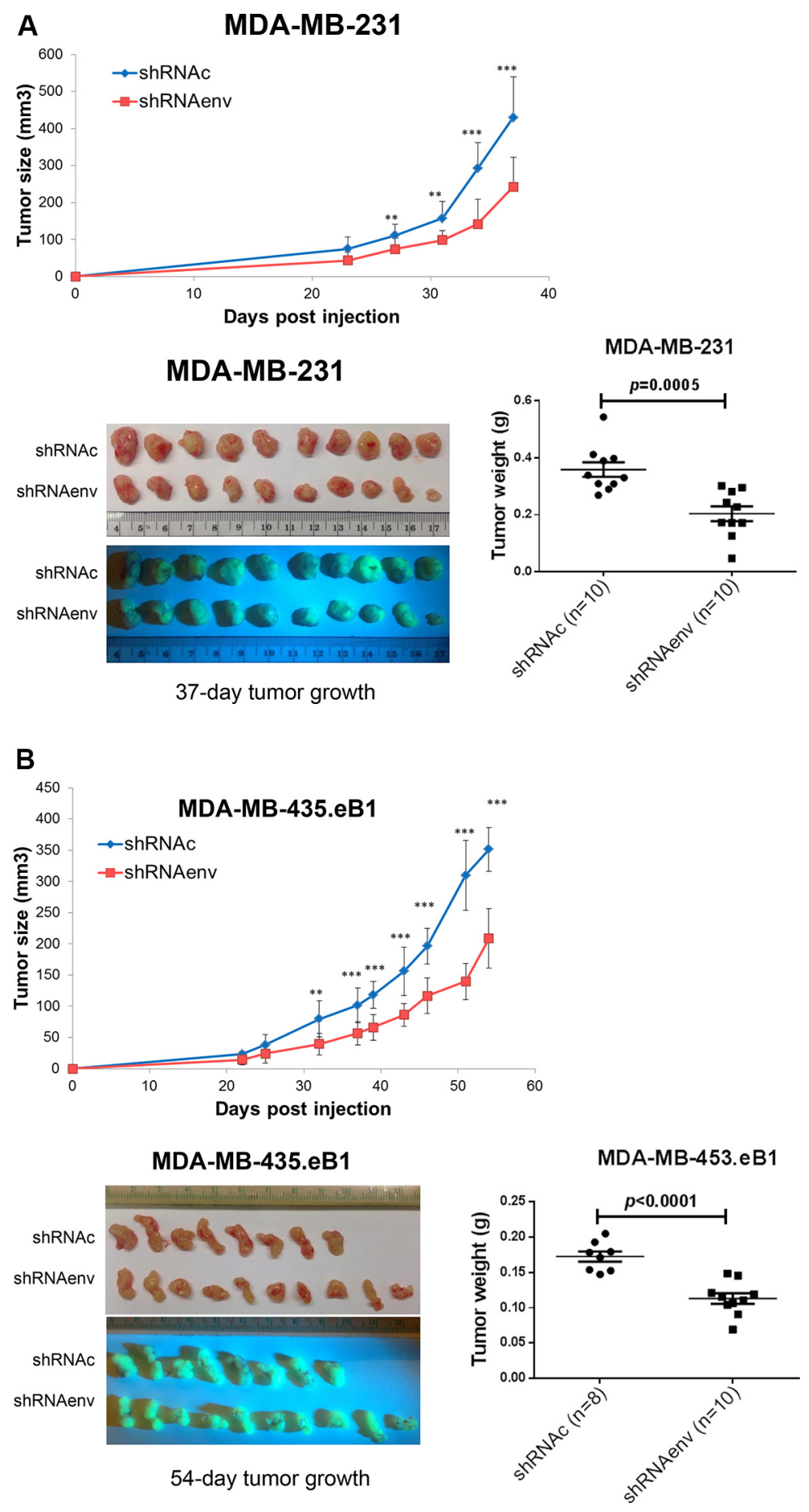


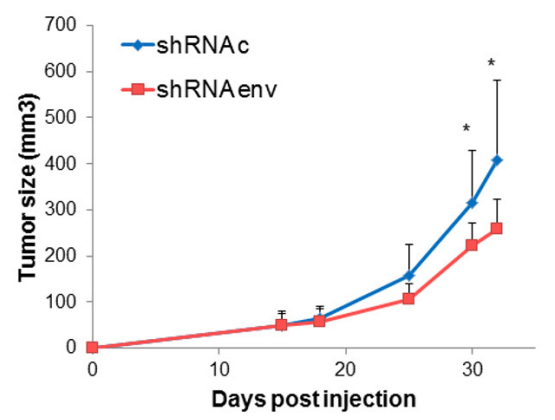

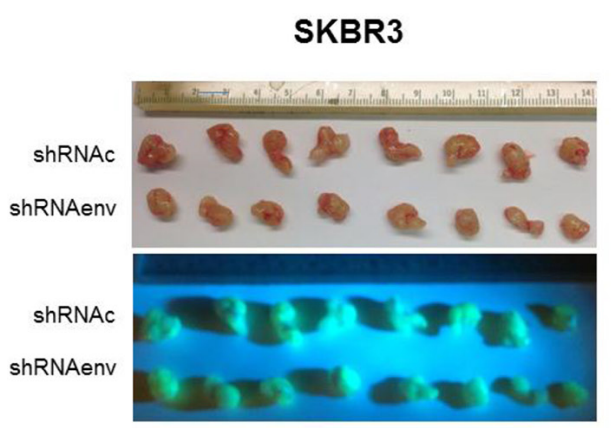

32-day tumor growth
SKBR3

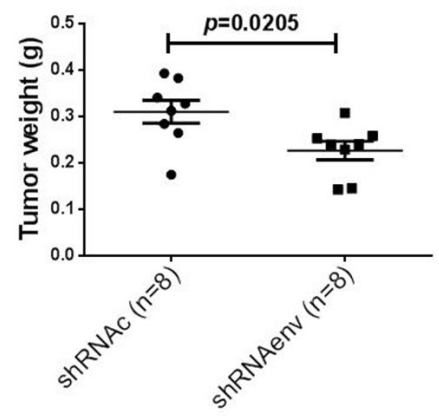

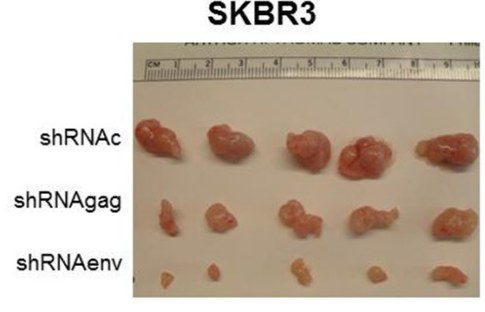
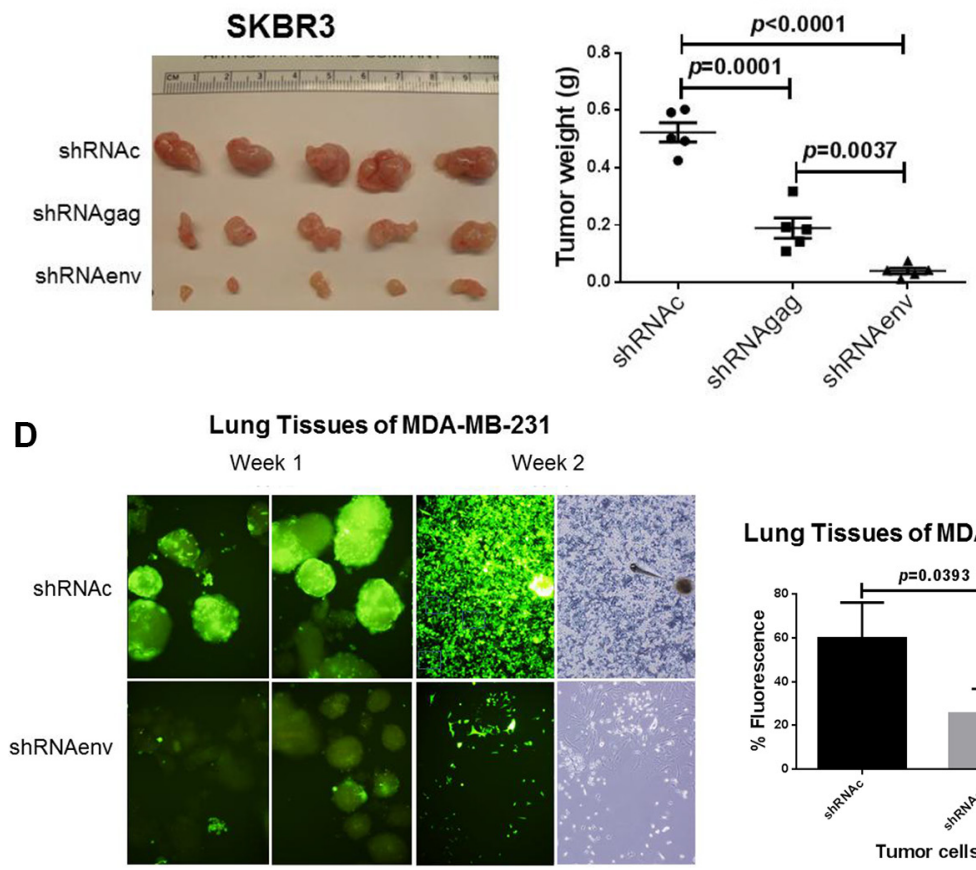

Lung Tissues of MDA-MB-231

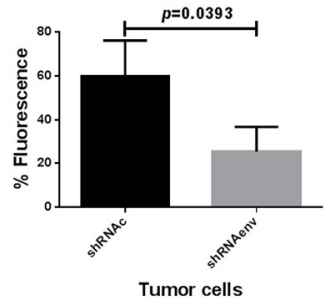

Figure 3: Effect of HERV-K knockdown on tumor growth in mouse xenografts. Significantly reduced tumor growth was observed in immunodeficient mice xenografted with MDA-MB-231 (A, top), MDA-MB-435.eB1 (B, top), and SKBR3 (C, top) cells transduced with shRNAenv, compared to cells transduced with shRNAc. Significantly reduced tumor sizes and weights were further demonstrated in these three BC xenografts of MDA-MB-231 (A, bottom right), MDA-MB-435.eB1 (B, bottom right), and SKBR3 (C) middle right) cells $(n=8-10$; unpaired $t$ test). Significantly reduced tumor sizes and weights were also demonstrated for xenografts bearing SKBR3 cells transduced with shRNAenv (3C, bottom right) or shRNAgag ( $n=5$; unpaired $t$ test). The blue panels show green fluorescence of tumors containing human cells, since BC cells were transfected with shRNAc or shRNAenv expression vectors, which contain a green fluorescent protein (GFP) tag. Tumor sizes and weights were lower in the shRNAenv knockdown mice than in the shRNAgag knockdown mice. Furthermore, reduced metastasis to lung was demonstrated in MDA-MB-231 shRNAenv xenografts compared with shRNAc (D; Week 1 and 2). Significantly higher percentages of fluorescent cells were observed in lungs of shRNAc vs, shRNAenv (Week $1 ; p=0.0393 ; n=3$; unpaired $t$ test). Green fluorescent cells indicate human MDA-MB-231 cells. 
A

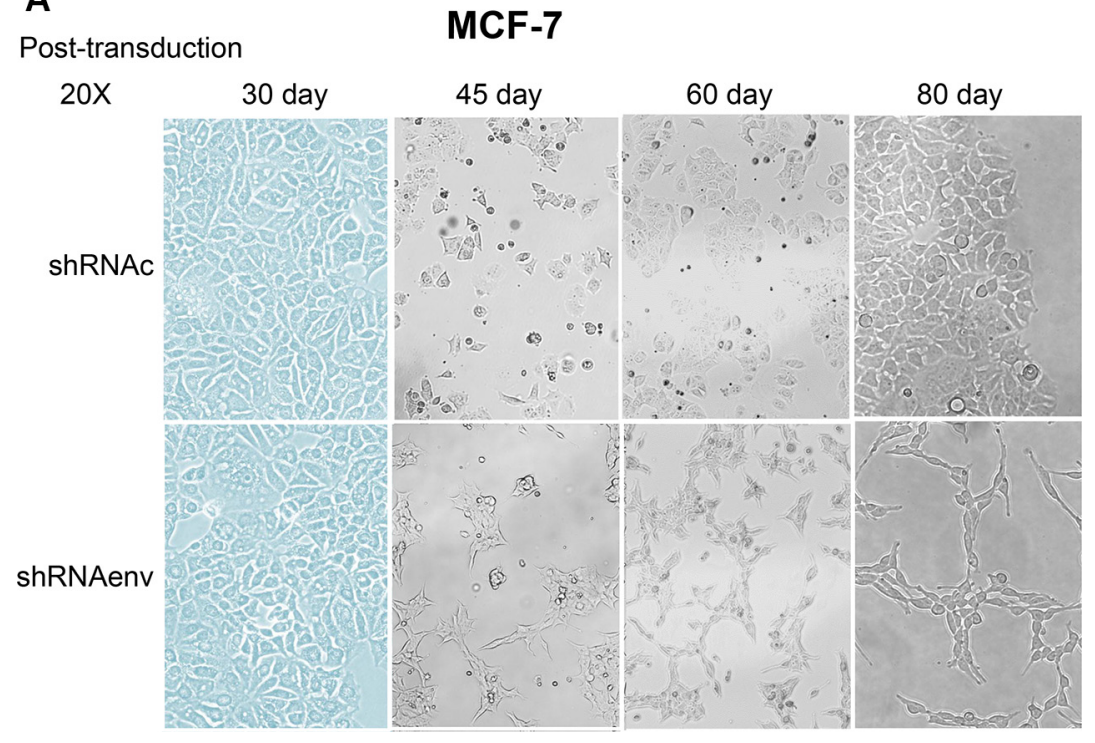

B

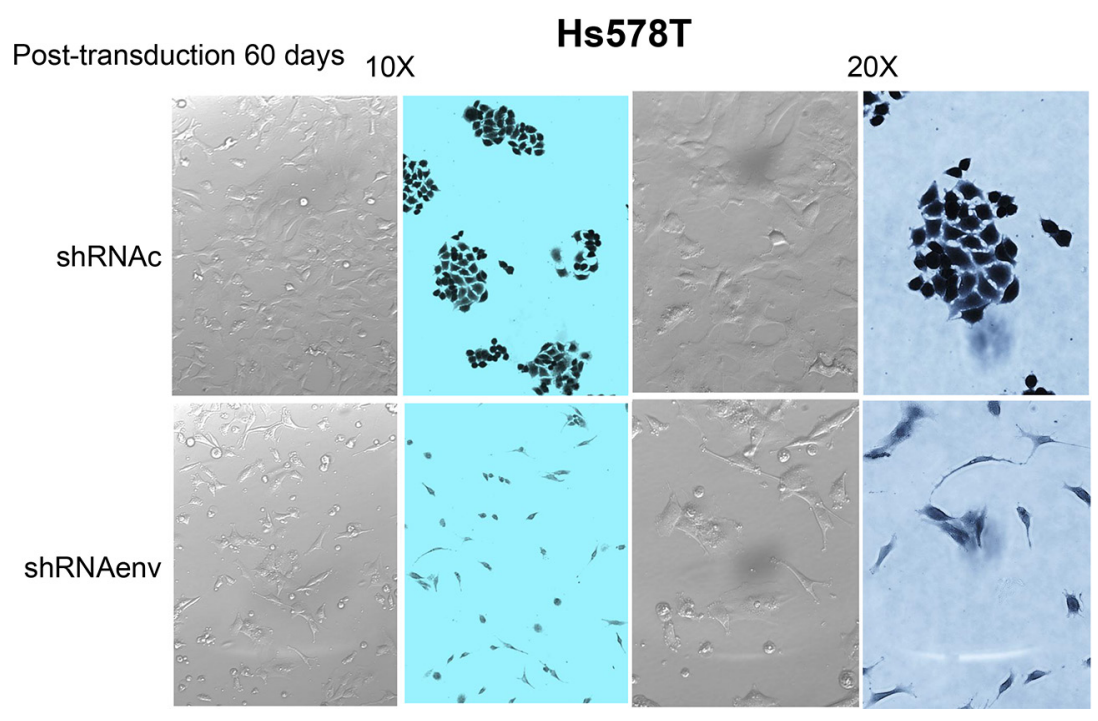

C

Post-transfected

MDA-MB-231

$20 \mathrm{X}$

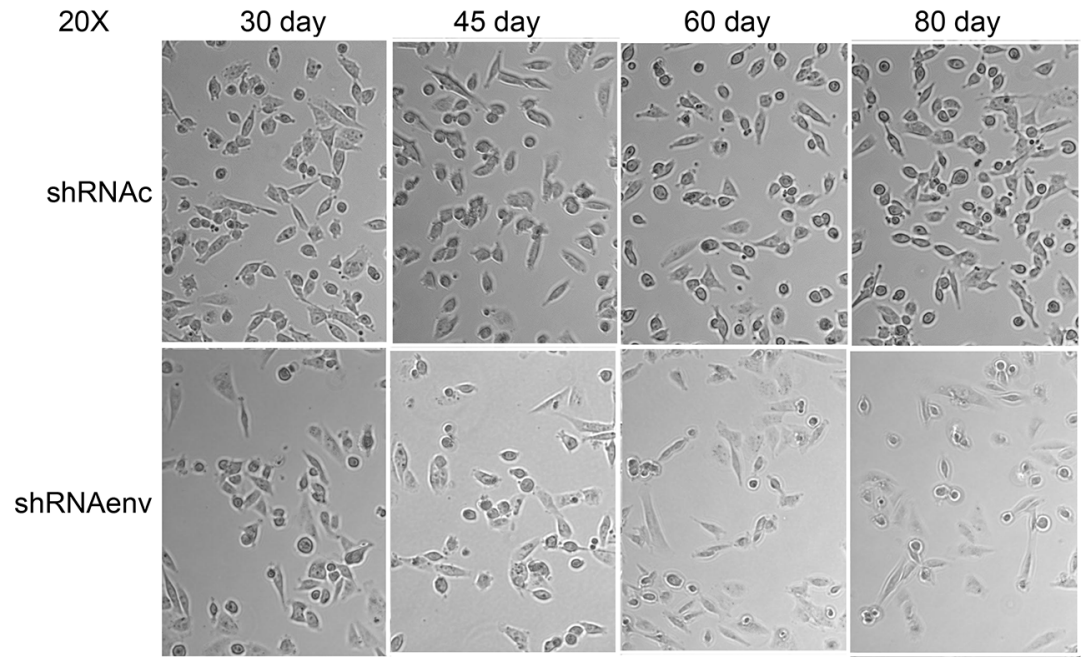

45 day

60 day

80 day 

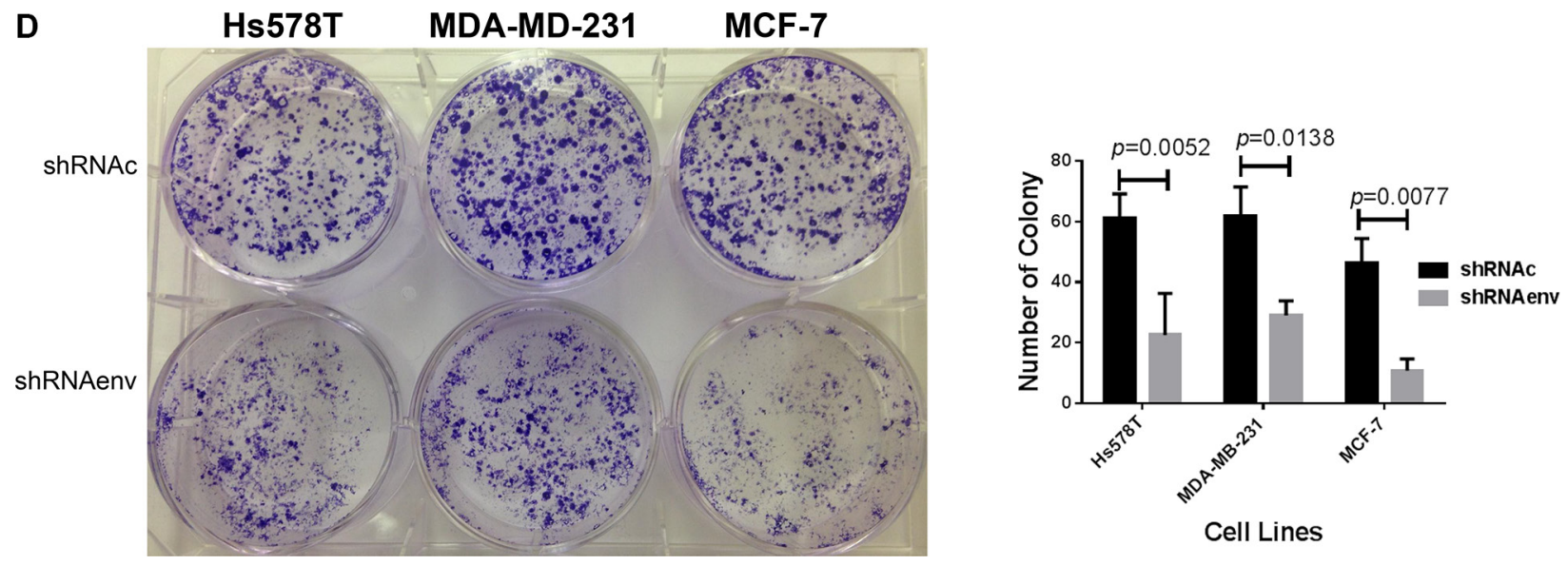

E

MCF-7

Hs578T

\section{MDA-MB-231}
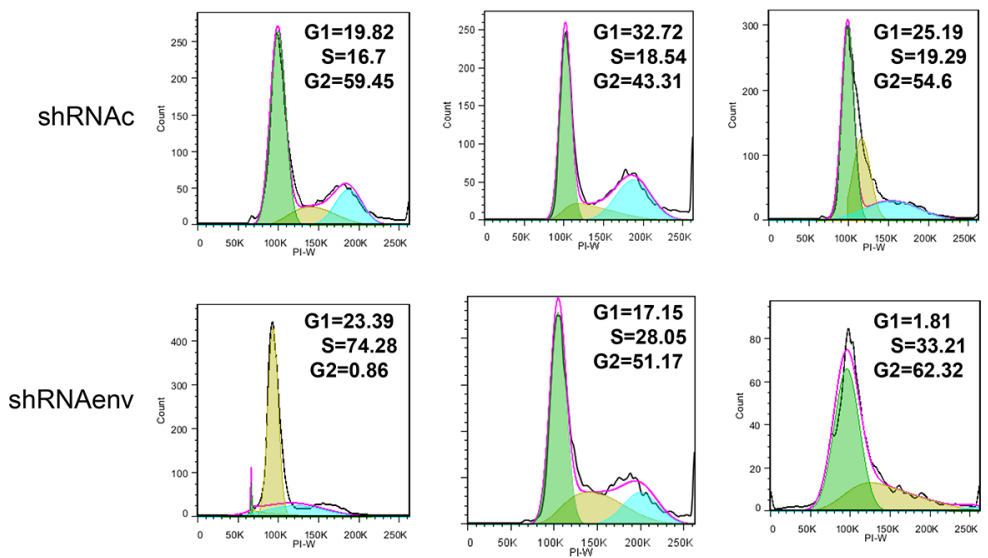

\section{MCF-7}

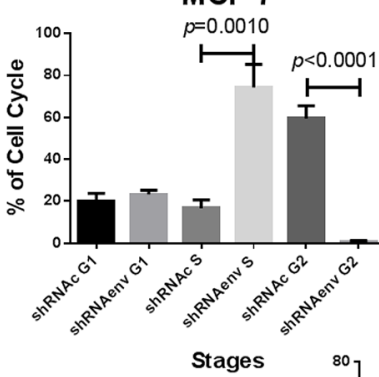

MDA-MB-231
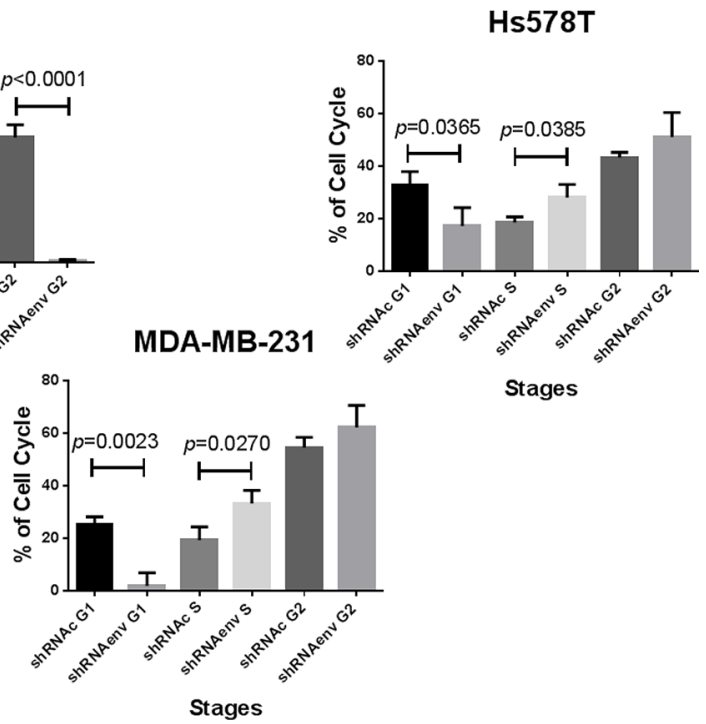

Figure 4: Phenotype changes in BC cells transduced with shRNAenv. Changes in phenotype in MCF-7 (A), Hs578T (B), and MDA-MB-231 (C) cells after HERV-K knockdown. Overall, significantly fewer and smaller sized colonies were observed in the three $\mathrm{BC}$ cell lines transduced with shRNAenv compared with shRNAc (D) Hs578T: $p=0.0052$; MDA-MB-231: $p=0.0138$; and MCF-7: $p=0.0077 ; n=4$; unpaired $t$ test) in the anchorage-independent colony formation assay. Furthermore, FACS analysis revealed significantly increased S phase arrest in the three cell lines after stable transfection with shRNAenv (E) $n=3$; unpaired $t$ test). Significantly decreased G1 phase arrest was observed in the two TNBC cell lines but not in the MCF-7 cells. A nonsignificant G2 phase arrest was observed in the two TNBC cell lines. 
Table 1: Ingenuity Pathways Analysis (IPA) of upstream regulators of differentially expressed genes between BC cell lines with and without knockdown of HERV-K env RNA

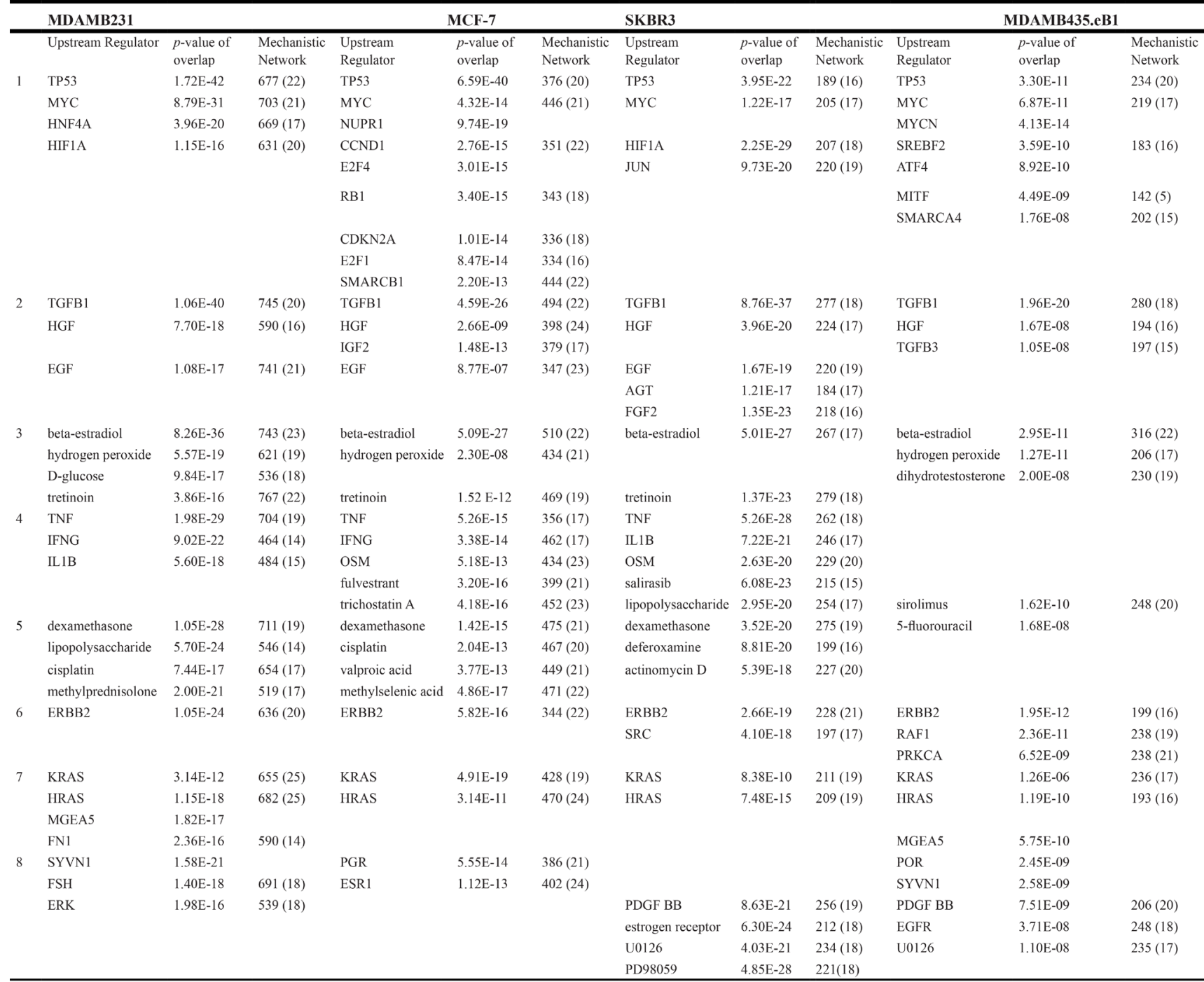

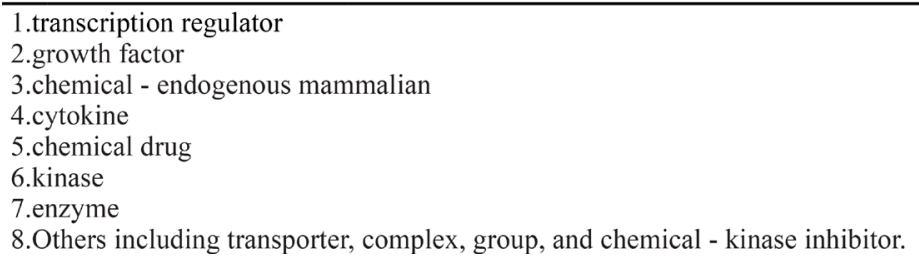

\section{Influence of HERV-K knockdown on expression of Ras and EMT markers in BC cell lines}

IFS was employed to detect the expression of HERV-K Env protein, Ras (antibody $27 \mathrm{H} 5$, which detects endogenous levels of total $\mathrm{K}$-, $\mathrm{H}$-, and N-Ras proteins), and EMT markers in cells after HERV-K knockdown by shRNAenv. Knockdown of HERV-K Env expression was accompanied by downregulation of Ras protein expression in three $\mathrm{BC}$ cell lines (Figure 5A-5C). To evaluate if this change was the result of an EMT, we tested for expression of EMT markers. HERV-K shRNA transduction led to decreased expression of CK19 and vimentin in the three BC cell lines. These data indicate that the phenotype change associated with shRNAenv treatment was not the result of an EMT, because shRNAenv led to reduced expression of both the characteristic mesenchymal marker vimentin and the characteristic epithelial marker CK-19.

\section{Downregulated expression of HERV-K env RNA blocked signaling via the Ras/Raf/MEK/ERK pathway}

Strong and significant reduction of K-Ras expression in SKBR3 (8.38E-10), MDA-MB-231 (3.14E-12), MDAMB-435.eb1 (1.26E-06) and MCF-7 (4.19E-19) cells, and of H-Ras in MDA-MB-435.eb1 (1.19E-10), MCF-7 (3.14E-11), SKBR3 (7.48E-15), and MDA-MB-231 (1.15E-18) cells 
Table 2: Ingenuity Pathways Analysis (IPA) functional annotation of differentially expressed genes between BC cell lines with and without knockdown of HERV-K env RNA

\begin{tabular}{|c|c|c|c|c|c|c|c|c|c|c|c|c|}
\hline & MDAMB231 & & & MCF-7 & & & SKBR3 & & & MDA-MB-435 & & \\
\hline 1 & $\begin{array}{l}\text { Functional Annotation } \\
\text { proliferation of cells }\end{array}$ & $\begin{array}{l}p \text {-Value } \\
6.47 \mathrm{E}-32\end{array}$ & $\begin{array}{l}\# \\
\text { Molecules } \\
687\end{array}$ & $\begin{array}{l}\text { Functional Annotation } \\
\text { proliferation of cells }\end{array}$ & $\begin{array}{l}p \text {-Value } \\
8.53 \mathrm{E}-25\end{array}$ & $\begin{array}{l}\text { \# Molecules } \\
431\end{array}$ & $\begin{array}{l}\text { Functional Annotation } \\
\text { proliferation of cells }\end{array}$ & $\begin{array}{l}p \text {-Value } \\
1.40 \mathrm{E}-29\end{array}$ & $\begin{array}{l}\text { \# Molecules } \\
236\end{array}$ & $\begin{array}{l}\text { Functional Annotation } \\
\text { proliferation of cells }\end{array}$ & $\begin{array}{l}p \text {-Value } \\
2.29 \mathrm{E}-11\end{array}$ & $\begin{array}{l}\# \\
\text { Molecules } \\
242\end{array}$ \\
\hline \multirow[t]{8}{*}{2} & apoptosis & $7.17 \mathrm{E}-28$ & 520 & apoptosis & $5.33 \mathrm{E}-19$ & 319 & apoptosis & $2.00 \mathrm{E}-26$ & 193 & necrosis & 4.87E-09 & 177 \\
\hline & necrosis & $6.53 \mathrm{E}-26$ & 506 & necrosis & $1.84 \mathrm{E}-18$ & 313 & necrosis & $2.56 \mathrm{E}-27$ & 187 & apoptosis & $5.05 \mathrm{E}-09$ & 184 \\
\hline & cell death & $4.23 \mathrm{E}-25$ & 620 & cell death & $8.61 \mathrm{E}-19$ & 385 & cell death & $2.17 \mathrm{E}-23$ & 215 & cell death & $1.93 \mathrm{E}-09$ & 222 \\
\hline & $\begin{array}{l}\text { apoptosis of tumor cell } \\
\text { lines }\end{array}$ & $2.58 \mathrm{E}-20$ & 259 & $\begin{array}{l}\text { cell death of tumor cell } \\
\text { lines }\end{array}$ & $2.31 \mathrm{E}-20$ & 213 & $\begin{array}{l}\text { cell death of tumor cell } \\
\text { lines }\end{array}$ & $1.47 \mathrm{E}-32$ & 139 & & & \\
\hline & $\begin{array}{l}\text { advanced malignant } \\
\text { tumor }\end{array}$ & $7.90 \mathrm{E}-22$ & 184 & $\begin{array}{l}\text { apoptosis of tumor cell } \\
\text { lines }\end{array}$ & $3.50 \mathrm{E}-20$ & 178 & $\begin{array}{l}\text { apoptosis of tumor cell } \\
\text { lines }\end{array}$ & $5.50 \mathrm{E}-28$ & 117 & & & \\
\hline & invasion of cells & $4.59 \mathrm{E}-20$ & 193 & & & & & & & & & \\
\hline & cell movement & $2.37 \mathrm{E}-19$ & 396 & & & & & & & & & \\
\hline & $\begin{array}{l}\text { proliferation of tumor cell } \\
\text { lines }\end{array}$ & $2.34 \mathrm{E}-18$ & 299 & & & & & & & & & \\
\hline \multirow[t]{11}{*}{3} & $\begin{array}{l}\text { cell death of tumor cell } \\
\text { lines }\end{array}$ & $1.01 \mathrm{E}-24$ & 328 & $\begin{array}{l}\text { breast or colorectal } \\
\text { cancer }\end{array}$ & $1.33 \mathrm{E}-21$ & 484 & epithelial neoplasia & $1.11 \mathrm{E}-29$ & 319 & benign neoplasia & $1.84 \mathrm{E}-08$ & 67 \\
\hline & $\begin{array}{l}\text { necrosis of epithelial } \\
\text { tissue }\end{array}$ & $8.07 \mathrm{E}-19$ & 149 & breast or ovarian cancer & $1.51 \mathrm{E}-19$ & 220 & carcinoma & $1.76 \mathrm{E}-28$ & 312 & epithelial neoplasia & $2.90 \mathrm{E}-08$ & 201 \\
\hline & cell survival & $9.11 \mathrm{E}-19$ & 286 & abdominal neoplasm & $8.96 \mathrm{E}-19$ & 655 & solid tumor & $5.52 \mathrm{E}-28$ & 313 & solid tumor & $3.64 \mathrm{E}-08$ & 196 \\
\hline & $\begin{array}{l}\text { cell viability of tumor cell } \\
\text { lines }\end{array}$ & $3.29 \mathrm{E}-18$ & 173 & epithelial neoplasia & $1.34 \mathrm{E}-18$ & 672 & Cancer & $4.66 \mathrm{E}-27$ & 346 & carcinoma & $3.76 \mathrm{E}-08$ & 192 \\
\hline & abdominal neoplasm & $6.37 \mathrm{E}-25$ & 1070 & carcinoma & $3.05 \mathrm{E}-18$ & 653 & metastasis & $5.95 \mathrm{E}-24$ & 73 & growth of tumor & $1.40 \mathrm{E}-07$ & 41 \\
\hline & Cancer & $1.20 \mathrm{E}-23$ & 1499 & abdominal cancer & $9.78 \mathrm{E}-18$ & 640 & growth of tumor & $1.84 \mathrm{E}-20$ & 55 & Cancer & $1.52 \mathrm{E}-07$ & 258 \\
\hline & epithelial neoplasia & $3.43 \mathrm{E}-19$ & 1072 & Cancer & $1.20 \mathrm{E}-17$ & 907 & & & & & & \\
\hline & digestive tract cancer & $8.56 \mathrm{E}-21$ & 771 & metastasis & $1.23 \mathrm{E}-14$ & 113 & & & & & & \\
\hline & & & & precancerous condition & $3.09 \mathrm{E}-14$ & 395 & & & & & & \\
\hline & abdominal cancer & $9.74 \mathrm{E}-23$ & 1042 & & & & & & & & & \\
\hline & & & & Gastrointestinal Tract & & & & & & & & \\
\hline \multirow[t]{11}{*}{4} & breast or colorectal cancer & $1.33 \mathrm{E}-22$ & 755 & Cancer and Tumors & $7.79 \mathrm{E}-16$ & 431 & digestive organ tumor & $1.88 \mathrm{E}-26$ & 147 & & & \\
\hline & metastasis & $4.88 \mathrm{E}-22$ & 183 & gastrointestinal tumor & $1.67 \mathrm{E}-15$ & 431 & intestinal cancer & $1.30 \mathrm{E}-19$ & 100 & & & \\
\hline & & & & digestive organ tumor & $2.71 \mathrm{E}-15$ & 478 & $\begin{array}{l}\text { gastrointestinal tract } \\
\text { cancer }\end{array}$ & $2.58 \mathrm{E}-19$ & 106 & & & \\
\hline & & & & $\begin{array}{l}\text { gastrointestinal tract } \\
\text { cancer }\end{array}$ & $4.15 \mathrm{E}-15$ & 425 & colorectal tumor & $1.17 \mathrm{E}-19$ & 100 & & & \\
\hline & & & & digestive tract cancer & $1.79 \mathrm{E}-14$ & 469 & & & & & & \\
\hline & & & & intestinal tumor & $1.96 \mathrm{E}-14$ & 395 & cell movement & $8.82 \mathrm{E}-32$ & 169 & invasion of cells & $1.25 \mathrm{E}-14$ & 81 \\
\hline & carcinoma & $1.77 \mathrm{E}-19$ & 1044 & cell movement & $3.48 \mathrm{E}-14$ & 246 & migration of cells & $2.05 \mathrm{E}-29$ & 154 & $\begin{array}{l}\text { invasion of tumor cell } \\
\text { lines }\end{array}$ & $4.97 \mathrm{E}-13$ & 62 \\
\hline & organismal death & 8.37E-21 & 455 & & & & $\begin{array}{l}\text { cell movement of } \\
\text { tumor cell lines }\end{array}$ & $6.97 \mathrm{E}-25$ & 84 & migration of cells & 2.13E-10 & 139 \\
\hline & $\begin{array}{l}\text { invasion of tumor cell } \\
\text { lines }\end{array}$ & $1.20 \mathrm{E}-18$ & 148 & & & & invasion of cells & $7.56 \mathrm{E}-24$ & 83 & $\begin{array}{l}\text { invasion of melanoma } \\
\text { cell lines }\end{array}$ & $1.05 \mathrm{E}-09$ & 17 \\
\hline & & & & & & & $\begin{array}{l}\text { invasion of tumor cell } \\
\text { lines }\end{array}$ & $3.26 \mathrm{E}-21$ & 65 & cell movement & $1.49 \mathrm{E}-09$ & 148 \\
\hline & & & & & & & $\begin{array}{l}\text { migration of tumor cell } \\
\text { lines }\end{array}$ & $3.36 \mathrm{E}-21$ & 68 & $\begin{array}{l}\text { invasion of breast cancer } \\
\text { cell lines }\end{array}$ & $2.29 \mathrm{E}-08$ & 27 \\
\hline \multirow[t]{12}{*}{6} & digestive organ tumor & $1.19 \mathrm{E}-20$ & 779 & mammary tumor & $2.14 \mathrm{E}-14$ & 189 & & & & & & \\
\hline & mammary tumor & $4.52 \mathrm{E}-19$ & 300 & & & & $\begin{array}{l}\text { proliferation of tumor } \\
\text { cell lines }\end{array}$ & $2.95 \mathrm{E}-20$ & 117 & $\begin{array}{l}\text { proliferation of tumor } \\
\text { cell lines }\end{array}$ & $4.92 \mathrm{E}-09$ & 113 \\
\hline & & & & cell cycle progression & $7.46 \mathrm{E}-15$ & 145 & & & & & & \\
\hline & & & & gonadal tumor & 7.47E-15 & 97 & $\begin{array}{l}\text { development of blood } \\
\text { vessel }\end{array}$ & $1.67 \mathrm{E}-20$ & 82 & $\begin{array}{l}\text { cell movement of } \\
\text { endothelial cells }\end{array}$ & $1.36 \mathrm{E}-09$ & 40 \\
\hline & & & & & & & vasculogenesis & $1.25 \mathrm{E}-19$ & 75 & vasculogenesis & $4.01 \mathrm{E}-09$ & 67 \\
\hline & & & & & & & & & & $\begin{array}{l}\text { development of blood } \\
\text { vessel }\end{array}$ & $9.10 \mathrm{E}-09$ & 72 \\
\hline & & & & & & & & & & $\begin{array}{l}\text { migration of endothelial } \\
\text { cells }\end{array}$ & $1.16 \mathrm{E}-08$ & 36 \\
\hline & & & & & & & & & & $\begin{array}{l}\text { adhesion of connective } \\
\text { tissue cells }\end{array}$ & $1.70 \mathrm{E}-07$ & 21 \\
\hline & & & & & & & & & & cell spreading & $3.18 \mathrm{E}-08$ & 33 \\
\hline & & & & & & & & & & organization & & \\
\hline & & & & & & & & & & cytoskeleton & $1.32 \mathrm{E}-07$ & 95 \\
\hline & & & & & & & & & & chronic kidney disease & $1.48 \mathrm{E}-07$ & 18 \\
\hline \multicolumn{13}{|c|}{ 1. Cellular Growth and Proliferation } \\
\hline & and Survival & & & & & & & & & & & \\
\hline & ancer & & & & & & & & & & & \\
\hline & & & & & & & & & & & & \\
\hline & & & & & & & & & & & & \\
\hline
\end{tabular}


Table 3: The phosphorylation profiles of kinases and their protein substrates in MCF-7 cells transduced with shRNAenv vs. shRNAc

\begin{tabular}{|c|c|c|c|}
\hline MCF-7 & shRNAc & shRNAenv & Ratio \\
\hline eNOS & 1 & 0.11064 & 0.11064182 \\
\hline RSK $1 / 2 / 3$ & 1 & 0.62695 & 0.6269543 \\
\hline HSP60 & 1 & 0.67656 & 0.67656339 \\
\hline STAT5a/b & 1 & 0.67902 & 0.67901655 \\
\hline Fyn & 1 & 0.74091 & 0.74091294 \\
\hline Lck & 1 & 0.77592 & 0.77591621 \\
\hline Lyn & 1 & 0.78501 & 0.78500609 \\
\hline p70 S6 Kinase & 1 & 0.7877 & 0.78769829 \\
\hline Hck & 1 & 0.80348 & 0.80347775 \\
\hline Akt 1/2/3 T308 & 1 & 0.81457 & 0.81457277 \\
\hline STAT3 S727 & 1 & 0.81635 & 0.8163504 \\
\hline$\beta$-Catenin & 1 & 0.82757 & 0.82756674 \\
\hline FAK & 1 & 0.83127 & 0.83127401 \\
\hline PDGF R $\beta$ & 1 & 0.86031 & 0.86030859 \\
\hline Chk-2 & 1 & 0.88314 & 0.88314166 \\
\hline CREB & 1 & 0.92764 & 0.92763798 \\
\hline STAT5a & 1 & 0.94686 & 0.94686027 \\
\hline Yes & 1 & 0.96352 & 0.96351656 \\
\hline STAT5b & 1 & 0.97903 & 0.97902745 \\
\hline PRAS40 & 1 & 0.97989 & 0.97989347 \\
\hline p53 S392 & 1 & 1.00648 & 1.00648388 \\
\hline p53 S46 & 1 & 1.01919 & 1.01918852 \\
\hline GSK- $3 \alpha / \beta$ & 1 & 1.02083 & 1.02082839 \\
\hline c-Jun & 1 & 1.02129 & 1.02129322 \\
\hline JNK 1/2/3 & 1 & 1.02866 & 1.02865523 \\
\hline p53 S15 & 1 & 1.04628 & 1.04627875 \\
\hline ERK1/2 & 1 & 1.04683 & 1.04683285 \\
\hline WNK1 & 1 & 1.05737 & 1.0573731 \\
\hline AMPK $\alpha 2$ & 1 & 1.0578 & 1.05779985 \\
\hline $\mathrm{Src}$ & 1 & 1.06922 & 1.06921719 \\
\hline STAT6 & 1 & 1.07413 & 1.07412904 \\
\hline STAT2 & 1 & 1.09571 & 1.09571017 \\
\hline STAT3 Y705 & 1 & 1.10981 & 1.10981287 \\
\hline Akt $1 / 2 / 3$ S473 & 1 & 1.15316 & 1.15316022 \\
\hline AMPK $\alpha 1$ & 1 & 1.15757 & 1.15756881 \\
\hline EGF R & 1 & 1.23593 & 1.23592759 \\
\hline TOR & 1 & 1.2745 & 1.27449869 \\
\hline HSP27 & 1 & 1.28963 & 1.2896269 \\
\hline Fgr & 1 & 1.31598 & 1.31597666 \\
\hline MSK1/2 & 1 & 1.41262 & 1.41262168 \\
\hline p38 & 1 & 1.70822 & 1.70821786 \\
\hline
\end{tabular}


after HERV-K knockdown was revealed by RNA-Seq assays (Table 1). Our RNA-Seq and IFS staining results suggested some important potential targets of HERV-K in $\mathrm{BC}$ cells, prompting us to pursue an investigation of changes in Ras/Raf/MEK/ERK pathway signaling resulting from knockdown of HERV-K.

A greater degree of HERV-K Env protein downregulation was associated with a correspondingly greater decrease in the expression of Ras in Hs578T, MDA-MB-231, MDA-MB-435.eB1, and MCF-7 cells (Figure 5D), as assessed by FACS. Reduced expression of HERV-K after knockdown with shRNAenv was associated with decreased expression of p-RSK, p-ERK1/2, and Ras in the three BC cell lines (Figure 5E and S5A), as assessed by immunoblot. HIF-1 $\alpha$ is also a driver of EMT, and its expression was downregulated in the 3 shRNAenvtransduced BC cell lines compared with shRNAc by immunoblot (Figure S5A). HIF-1 $\alpha$ expression is associated with increased proliferation, and has an adverse prognostic impact with increased concentrations in invasive ER-positive breast cancer [15]. Downregulation of HIF-1 $\alpha$ expression by shRNA inhibited proliferation, migration, and invasion of cancer cells in vitro, and decreased tumor growth in breast cancer xenograft models [16]. In addition, there was increased expression of EpCAM in MCF-7 and Hs578T cells transduced with shRNAenv (data not shown), but during the progression of EMT both EpCAM and CK are downregulated.

\section{Upregulated expression of HERV-K induced BC cell invasion and migration}

Since downregulated expression of HERV-K env RNA reduced the migration and invasion of $\mathrm{BC}$ cells, we further investigated the changes in these processes after restoring the expression of HERV-K env by transducing cells with a HERV-K env expression vector (+pLVXKenv; Figure S5B) or a vector with a synonymous mutant of HERV-K env (+pLVX-Kmut), whose purpose was to show specificity for shRNAenv, since the shRNAenv cannot knock down Kmut. Vector only $(+\mathrm{pLVX})$ or untreated cells were used as controls. Increased migration was demonstrated in MCF-7 shRNAc cells transduced with either $\mathrm{pLVX}-\mathrm{Kenv}(p=0.048)$ or pLVX-Kmut $(p=0.039)$, compared to untreated cells or cells with added vector only $(+\mathrm{pLVX})$ (Figure 6A, top left and top right panels). However, migration was increased only in MCF-7 shRNAenv cells with added pLVX-Kmut $(p=0.002)$, and not in MCF-7 shRNAenv cells transduced with the non-mutated expression vector pLVX-Kenv. Similarly, increased invasion was demonstrated in MCF7 shRNAc cells with added pLVX-Kenv $(p=0.043)$ and pLVX-Kmut $(p=0.039)$, compared with untreated cells or cells with added vector only $(+\mathrm{pLVX})$, but invasion was increased only in MCF-7 shRNAenv cells with added pLVX-Kmut $(p=0.001)$, and not in MCF-7 shRNAenv cells with added pLVX-Kenv (Figure 6A, bottom left and bottom right panels).

\section{Increased transformation of $\mathrm{BC}$ cells after HERV-K env transduction}

We further investigated BC cell transformation using an anchorage-independent growth assay, after shRNAenv or shRNAc cells had been transduced with HERV-K env gene. Larger colonies were observed in shRNAenv or shRNAc MCF-7 (Figure 6B, top panel), Hs578T (Figure 6C, top panel), and MDA-MB-231 (Figure 6D, top panel) cells transduced with pLVX-Kenv and pLVX-Kmut, in comparison to cells transduced with control plasmids that did not express HERV-K. When comparing shRNAc cells with shRNAenv cells, shRNAc cells formed larger colonies than shRNAenv transduced with pLVX-Kenv and pLVXKmut (Figure 6B-6D, top panel). Significantly reduced colony numbers were observed in the cells transduced with shRNAenv compared with shRNAc ( $p=0.0004$ for Hs578T, $p<0.0001$ for MCF-7, and for MDA-MB-231 cells). In contrast, significantly increased colony numbers were observed in shRNAenv or shRNAc cells transduced with pLVX-Kmut and in shRNAc cells transduced with pLVX-Kenv. MCF-7 cells (derived from adenocarcinoma metastatic site) were not as invasive as MDA-MB-231 cells in our assay (Figure 6A), and MCF-7 cells showed no metastasis in animal xenograft models (data not shown). However, when we overexpressed HERV-K the invasion in this cell line increased substantially, which may in part explain why HERV-K promotes invasion and metastasis. Of great importance, knockdown of HERV-K with shRNAenv reversed this increase in invasiveness that was induced by overexpression of HERV-K (+pLVX-Kenv), but not by overexpression of HERV-K with mutation (+pLVX-Kmut).

Immunoblotting revealed increased expression of HERV-K Env protein and other proteins including HIF-1 $\alpha$, p-RSK, p-ERK1/2, and Ras in shRNAc cells transduced with pLVX-Kenv and pLVX-Kmut (MCF-7 cells, Figure 6E and Figure S5C). However, increased expression of these proteins was only observed in the shRNAenv cells with added pLVX-Kmut, and not in shRNAenv cells transduced with pLVX-Kenv.

\section{Increased metastasis of $\mathrm{BC}$ cells expressing the HERV-K env gene in vivo}

No significant change in tumor growth and weights was seen in xenografts of MDA-MB-231 cells stably transfected with pLVX-Kenv vs. vector only (pLVX) (Figure 7A and 7B). Body weight was similarly unaffected in these mice bearing tumors expressing HERV-K (Figure 7C); there was a trend toward increased brain, spleen, and liver weight in these mice (Figure S6A-S6C). However, no significant differences between the groups 


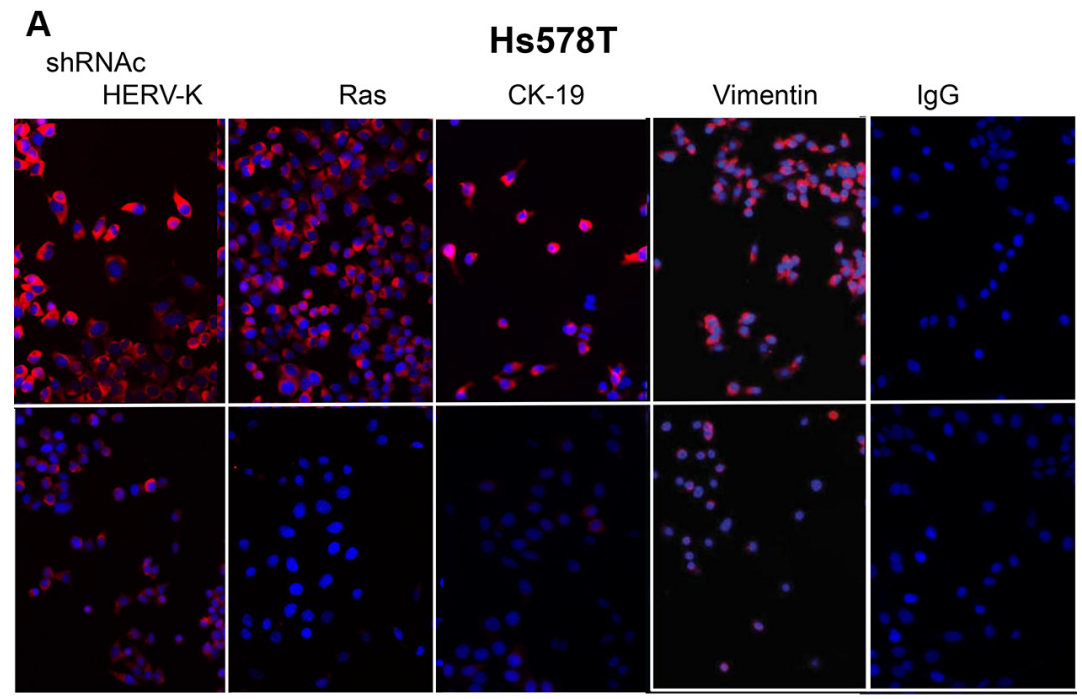

shRNAenv

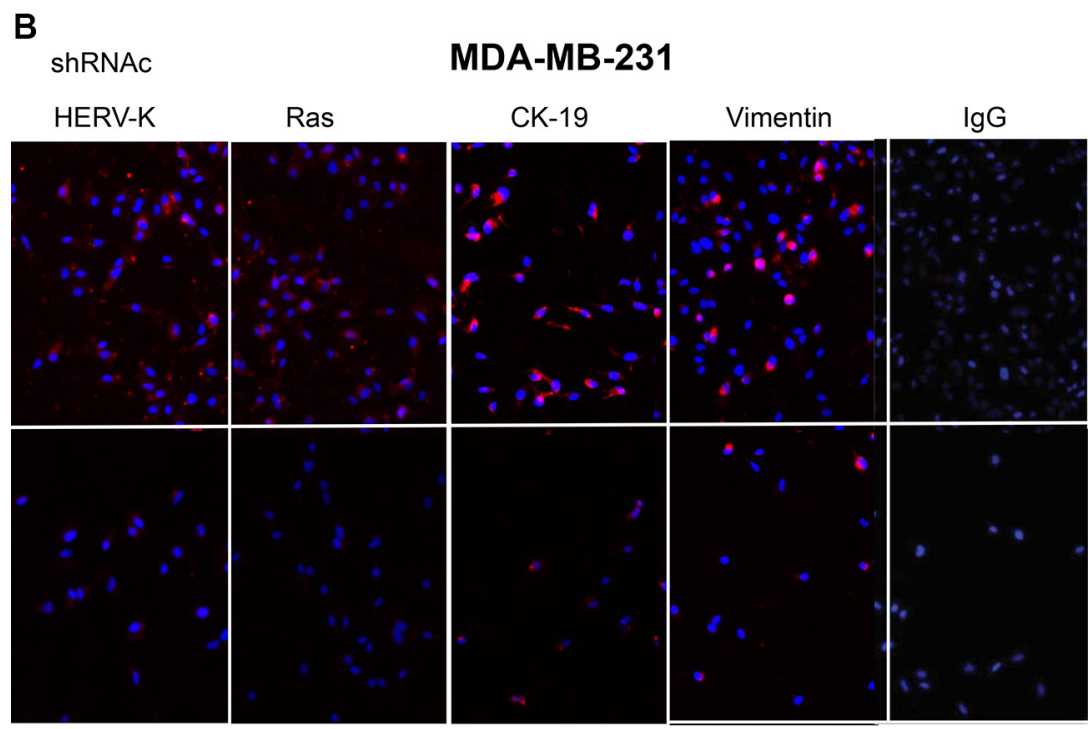

shRNAenv

C ShRNAC MCF-7

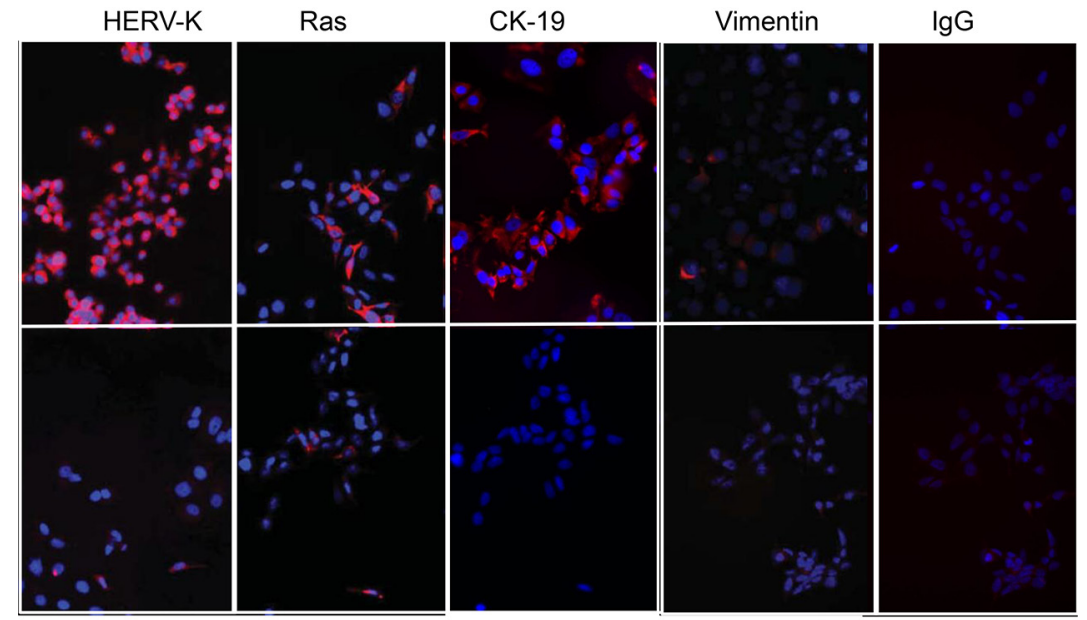

shRNAenv 
D

Hs578T MDA-MB-231 MDA-MB-435.eB1 MCF-7
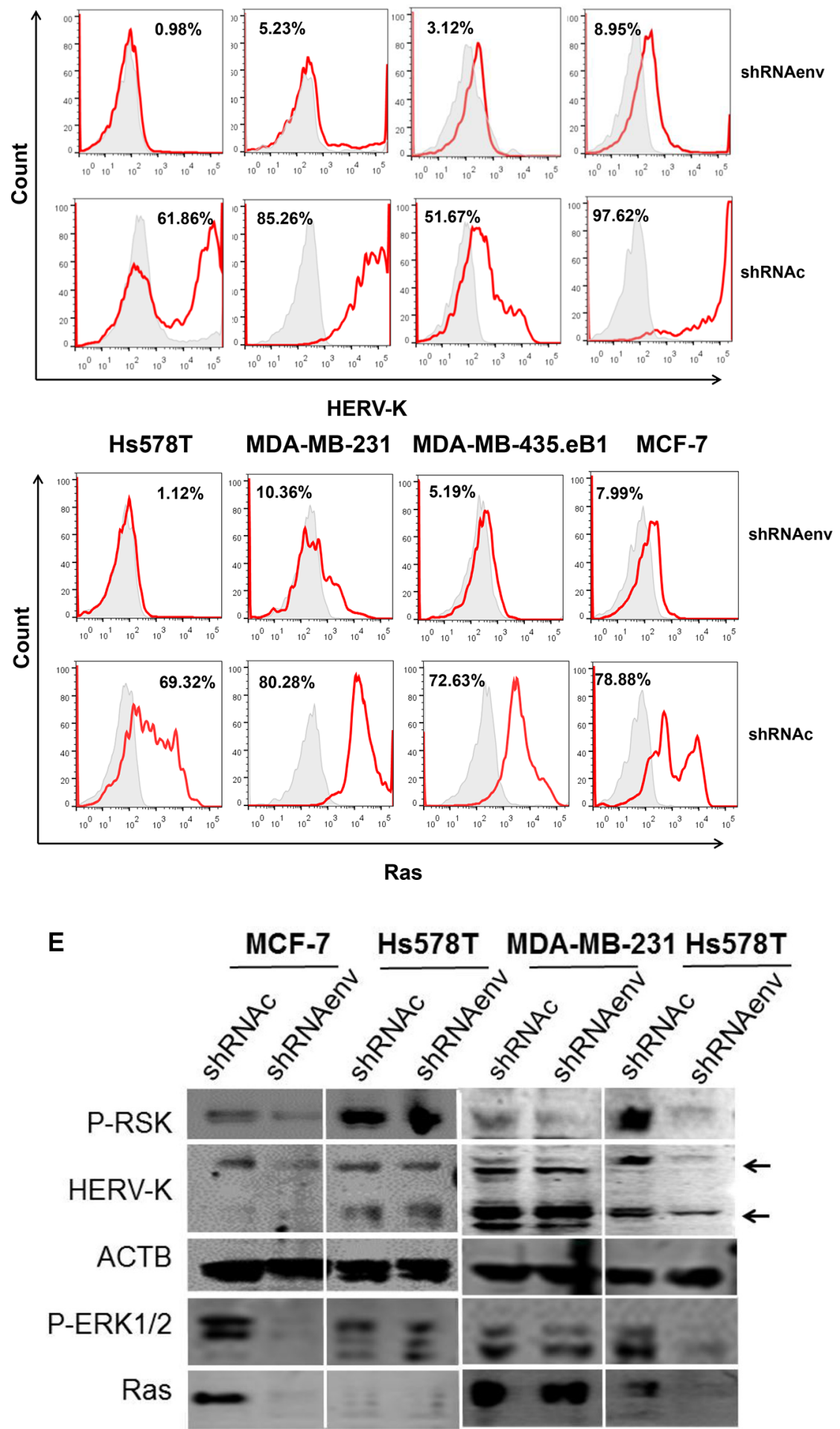

Figure 5: Changes in expression of signaling proteins after shRNA knockdown of HERV-K. IFS was used to detect changes in expression of HERV-K and Ras in Hs578T (A) MDA-MB-231 (B), and MCF-7 cells (C) after HERV-K knockdown. The effect of HERV-K knockdown on expression of proteins involved in EMT, including CK-19 and vimentin was determined in the three BC cell lines. Reduced protein expression was observed for all of these proteins. In addition, decreased Ras protein expression (D, left) was induced by downregulation of HERV-K expression (D, right) in cancer cells transduced with shRNAenv, as assessed by FACS (D). Immunoblot analysis showed reduced expression of p-RSK, p-ERK 1 or 2, and Ras in shRNAenv transduced MCF-7, MDA-MB-231, and Hs578T cells only when there was also shRNAenv-induced reduced expression of HERV-K Env protein in these cell lines (E). ACTB antibody was used as control. 
in other organs were detected (Figure S6D and S6E). Of interest, upregulated expression of HERV-K accompanied downregulated expression of p53 and upregulated expression of CDK5 in these MDA-MB-231 +Kenv tumors, compared with the same cells + pLVX controls (Figure 7D). More metastasis to lung was detected in lung after HERV-K overexpression (Figure 7E). A summary of pathways related to HERV-K Env protein is shown in Figure 7F.

\section{DISCUSSION}

The current study has provided strong evidence for an important role of HERV-K in human tumorigenesis. This is in agreement with several recent studies documenting key functions of HERVs in sensitization to immunotherapy [17], targeting of cancer-initiating cells [18], and promoting cytolytic activity in multiple tumor types [19].

Our RNA-Seq data support the role(s) of HERV-K env expression in promoting $\mathrm{BC}$ tumorigenesis by providing links with p53, Myc, and Ras signaling pathways. Our pathway analysis of HERV-K knockdown BC cell lines, based on the RNA-seq data, demonstrates that HERV-K facilitates maintenance of the transformed phenotype and promotes metastasis by promoting key signaling pathways involved in cellular movement, cancer, cell death/survival, and cell growth/proliferation. The data obtained from the phosphorylation profiles of kinases in HERV-K knockdown BC cells further support the involvement of the signaling pathways identified by our RNA-Seq analyses.

In a previous study we reported that treatment of $\mathrm{BC}$ cells with an anti-HERV mAb impacted p53 signaling pathways [6], a finding supported by our recent HERV-K-chimeric antigen receptor (K-CAR) studies showing that HERV-K affects tumorigenesis via a similar mechanistic effect on p53 signaling [8]. Our RNA-seq results additionally suggest important roles of TGF- $\beta 1, \beta$-estradiol, dexamethasone, TNF, and ERBB2 in mediating the effect of HERV-K knockdown in BC cells. There is little in the literature linking TGF- $\beta 1$ to endogenous retroviruses, although our RNA-Seq data suggest that it plays a very important mechanistic role in mediating HERV signaling in $\mathrm{BC}$, and that the relationship between HERV-K and TGF- $\beta 1$ in $\mathrm{BC}$ is deserving of further study. It has already been established by us and others that female hormones including $\beta$-estradiol increase the expression of HERV-K $[3,20]$. We previously reported that there was a greatly increased frequency of TNF- $\alpha-$ secreting CD8+ T cells in HERV-K-stimulated PBMCs from $B C$ patients, indicating a role for HERV-K in TNF- $\alpha$ secretion [5]. HERV-K and ERBB2 are both expressed in $\mathrm{BC}$, but there has not been a detailed analysis of their co-expression in $\mathrm{BC}$, and we have found a much broader expression pattern of HERV-K than that of ERBB2 in BC.

The Ras/Raf/MEK/ERK pathway is known to play a pivotal role in differentiation, proliferation and tumor progression. HERV-K Env protein downregulation correlated with downregulation of p-ERK protein in most of the mice treated with K-CAR T cells [8]. In an earlier study, knockdown of wild-type p53 led to activation of p-ERK1/2 [21], showing a reciprocal relationship similar to what we observed in the current study. The Ras/Raf/ MEK/ERK signaling pathway has been proposed to play an important role in HERV-K activation [22]. These observations may thus provide a mechanistic explanation of the role(s) HERV-K plays in breast tumorigenesis.

The link between HERV-K and Ras signaling was more firmly established in this study. Ras genes are among the most frequently mutated proto-oncogenes in cancer, and Ras proteins (K-Ras, H-Ras, and N-Ras) are known to regulate a number of processes that govern cancer progression, including cell proliferation, transformation, differentiation, and survival [23, 24]. However, how Ras stability is regulated remains largely unknown. Ras mutants trigger activation of downstream signaling pathways, thereby promoting cancer development. The MAPK/ERK pathway and PI3K/Akt pathway are two essential components in Ras-induced transformation and tumorigenesis [25]. Although Ras mutations are very rare in human $\mathrm{BCs}$, the Ras signaling pathway is hyperactivated in half of these tumors [26], and most of the effector pathways activated by Ras mutations promote cell growth and contribute to malignant transformation $[27,28]$. Ras may be more frequently activated by other mechanisms in these tumors, but the mechanism(s) by which Ras becomes activated in $\mathrm{BC}$ has remained elusive [26]. Although Ras mutations are rare in BC, amplifications of wild type Ras are frequently observed in basal BCs [29], the most aggressive subtype of human $\mathrm{BC}$, underscoring the connection between Ras activation and $\mathrm{BC}$ progression.

Previously, we and others have reported that HERV-K Env protein may serve as an oncogene that promotes tumor proliferation and metastasis in BC and other cancers. Our current study provides convincing evidence that HERV-K specifically increases Ras-induced ERK activation, and suggests that the oncogenic activity of Ras protein is propagated by activation of HERV-K Env protein. Importantly, the expression of HERV-K Env protein in metastatic tumor tissues treated with K-CAR $T$ cells correlated with the expression of Ras, and this HERV-K-specific CAR prevented tumor metastasis to other organs. Furthermore, downregulation of HERV-K expression in tumors of mice treated with K-CAR correlated with upregulation of p53 and downregulation of MDM2, p-ERK, and Ras [8].

Because overexpression of HERV-K is essential for promoting tumorigenesis, and shRNA knockdown of HERV-K expression eliminates the tumorigenic effect of HERV-K in Ras-initiated cancers, our studies reveal a fundamental role of HERV-K Env protein in regulating the Ras signaling pathway. Activation of HERV-K Env protein 

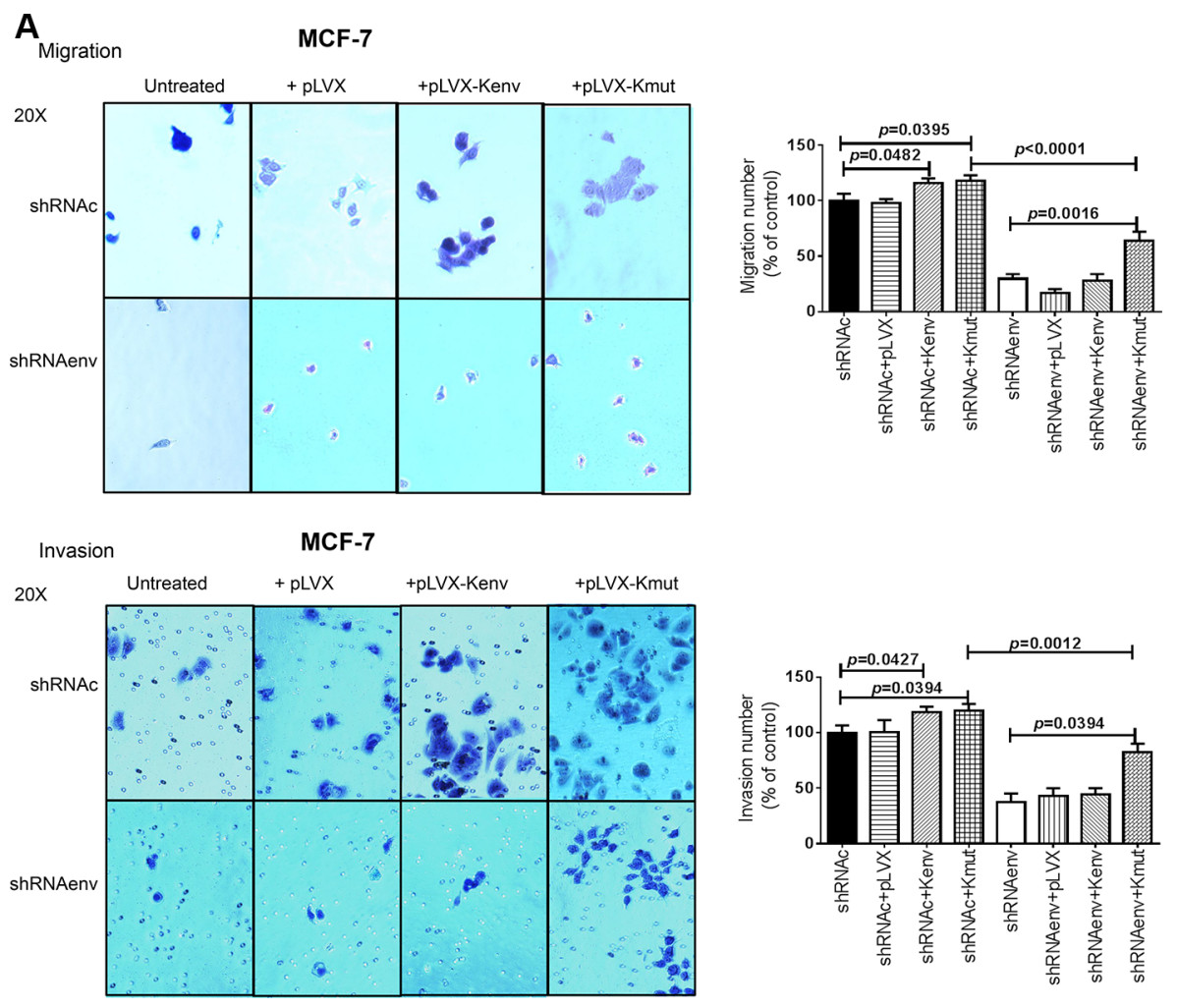

B

MCF-7
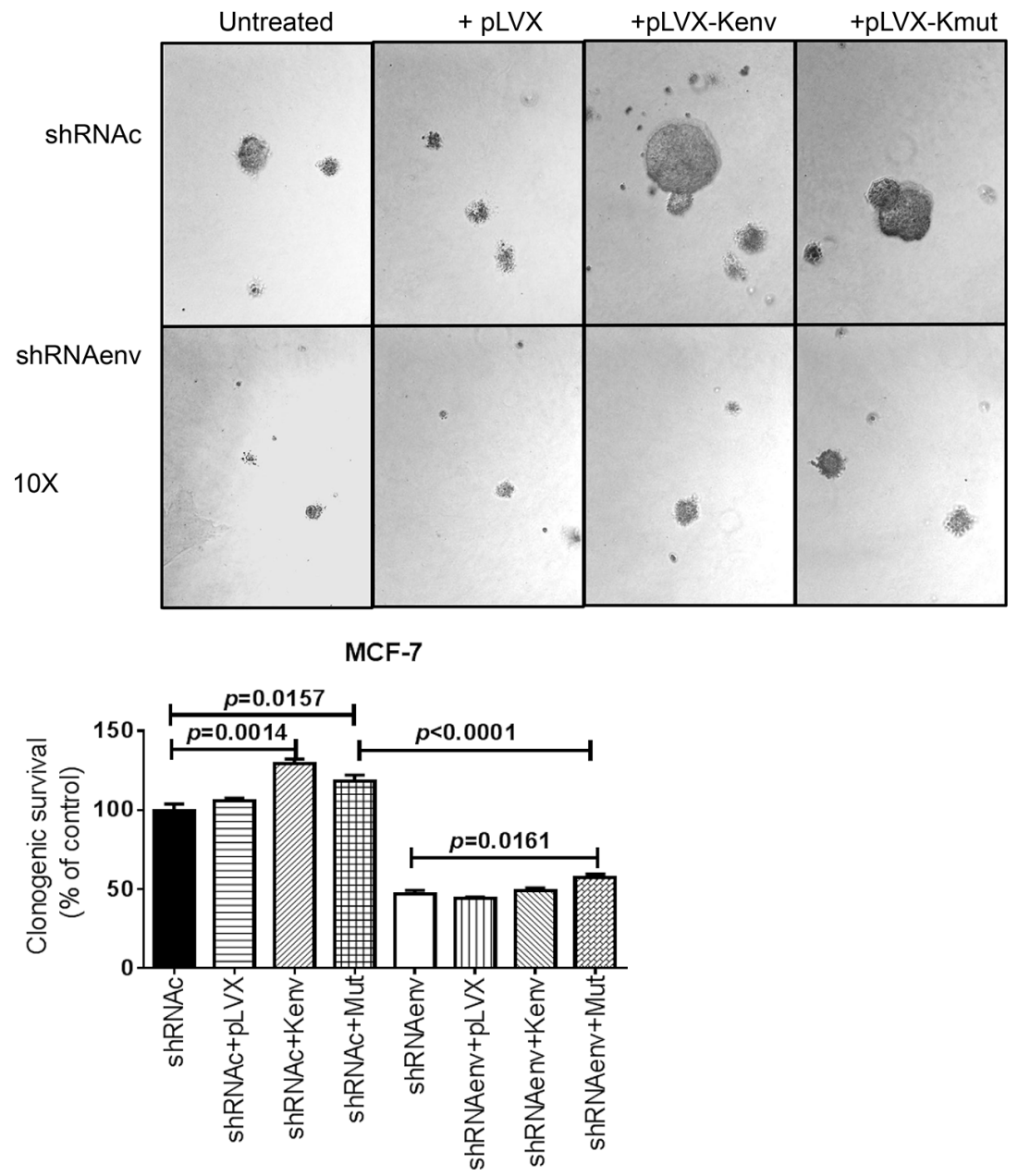
C
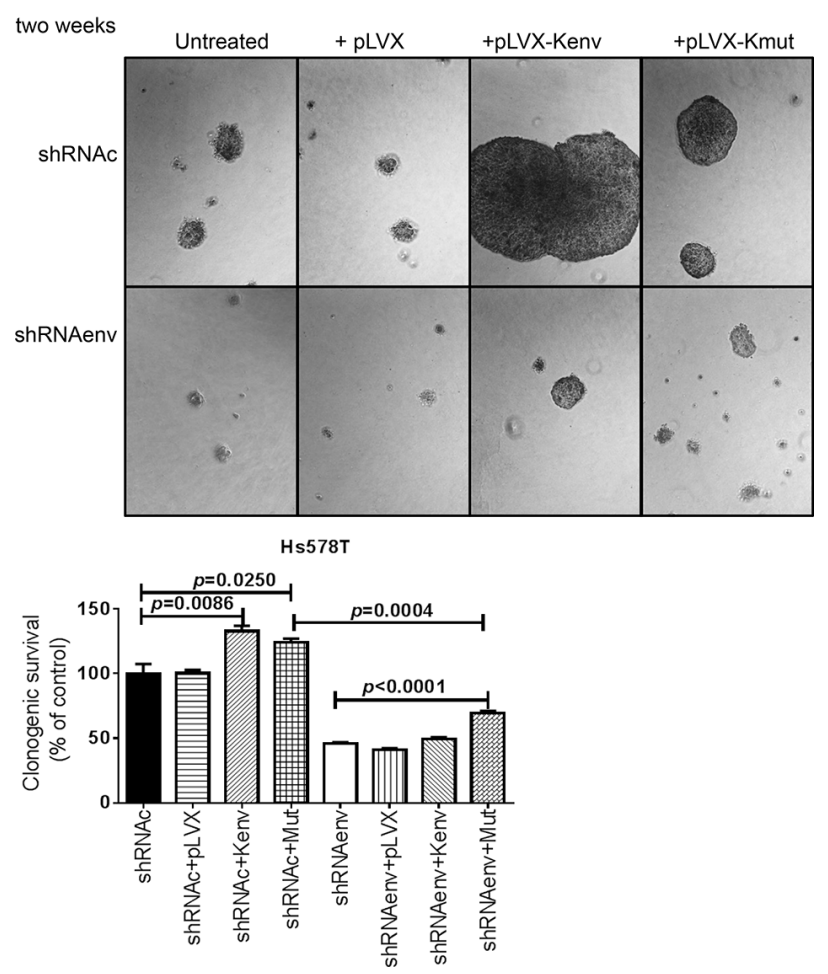

D
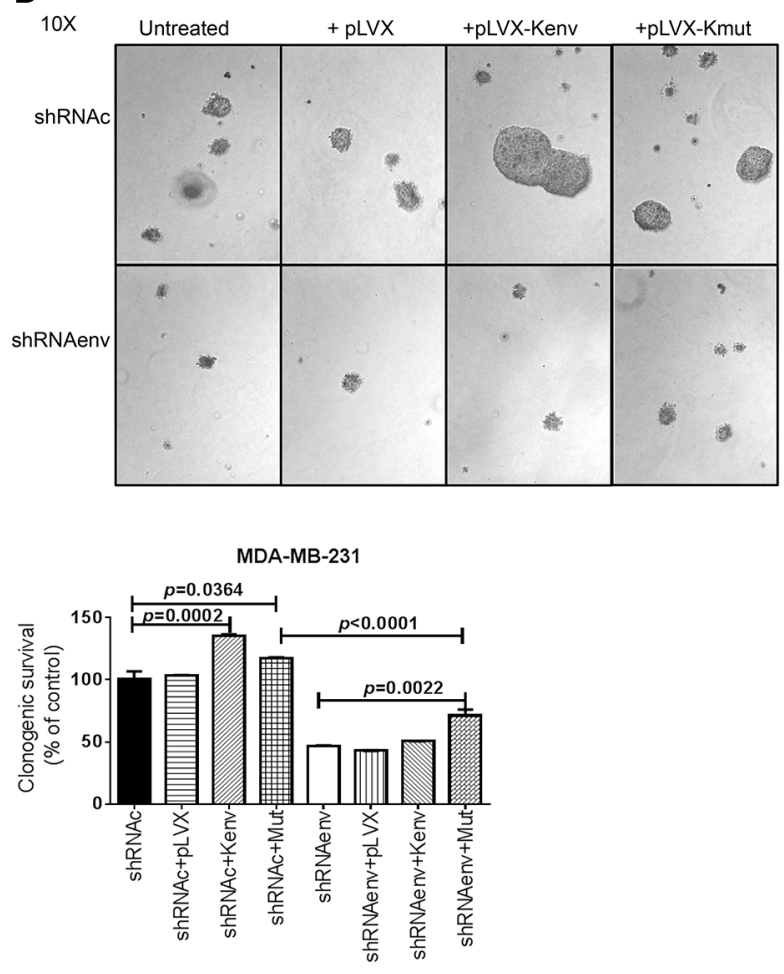

E

\section{MCF-7}

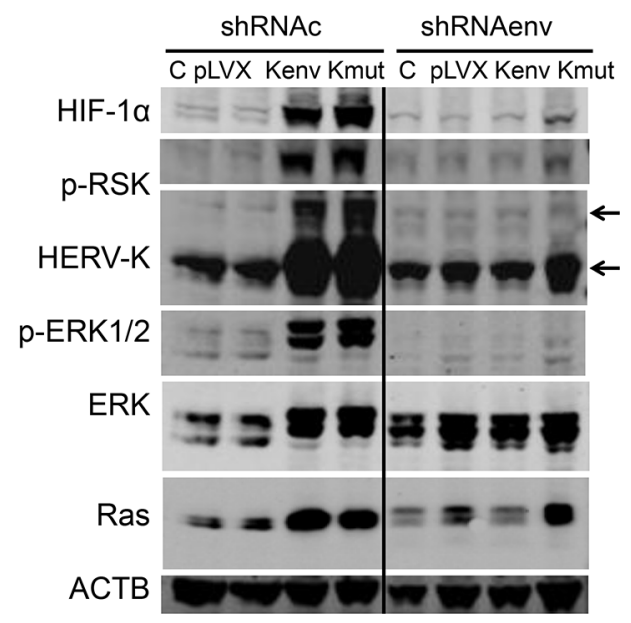

Figure 6: Effect of overexpression of HERV-K on in vitro migration, invasion, and transformation in cancer cells. Significantly decreased migration ( $p<0.0001$; (A, top right) and invasion $(p<0.0001$; A, bottom right) of MCF-7 cells stably transduced with shRNAenv was observed, compared with cells transduced with a scrambled shRNAc vector. Migration and invasion was increased if shRNAc cells were transduced with an HERV-K env expression vector [+Kenv; $p=0.0482$ for migration (A, top right) and $p=0.0427$ for invasion (A, bottom right)] or a vector expressing a mutated env gene [+Kmut; $p=0.0395$ for migration (A, top right) and $p=0.0394$ for invasion (A, bottom right) ( $n=11$; unpaired $t$ test)]. Untreated and vector only ( $+\mathrm{pLVX})$ were used as controls. No significant change was observed in shRNAenv cells transduced with Kenv, likely due to continued shRNAenv knockdown in these cells even in the presence of higher levels of Kenv. Significant change was observed in shRNAenv cells transduced with Kmut for migration $(p=0.0016)$ and invasion $(p=0.0394)$. Anchorage-independent growth assays were employed to determine cell transformation after BC cells were transduced with HERV-K env or mutated env gene. Images were taken 2 weeks post-seeding of cells in soft agar. Larger colonies and significantly increased numbers of colonies were observed for shRNAc cells after transduction with Kenv or Kmut in MCF-7 shRNAc $(p=0.001$ and $p$ $=0.016$, respectively; Figure B), Hs578T shRNAc $(p=0.0086$ and $p=0.025$, respectively; Figure C), and MDA-MB-231 $(p=0.0002$ and $p=0.036$, respectively; Figure D) cells. Significantly increased numbers of colonies were observed for shRNAenv cells transduced with Kmut in MCF-7 (B: $p=0.001)$, Hs578T (C; $p<0.0001$ ), and MDA-MB-231 (D; $p=0.002)$ cells $(n=4$; unpaired $t$ test). (E) Immunoblot assays showed increased levels of HIF-1alpha, p-RSK, HERV-K, p-ERK 1 or 2, and Ras protein in MCF-7 shRNAc cells transduced with Kenv or Kmut and in MCF-7 shRNAenv cells transduced with Kmut. The deviation (error bars) represents standard error of the mean (SEM). 
A

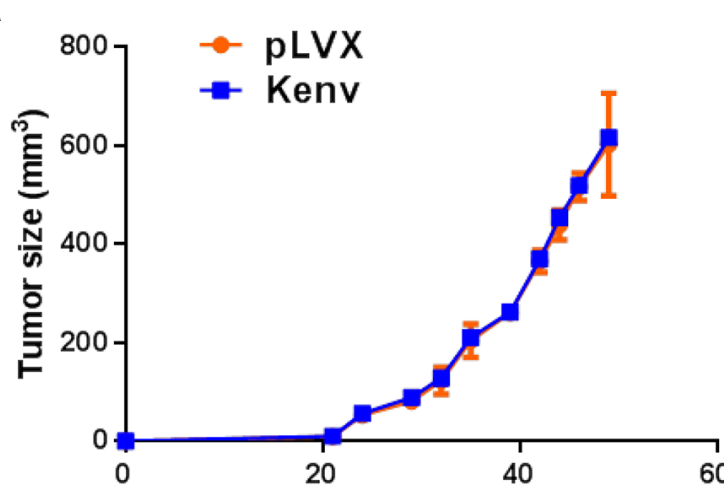

Days post injection

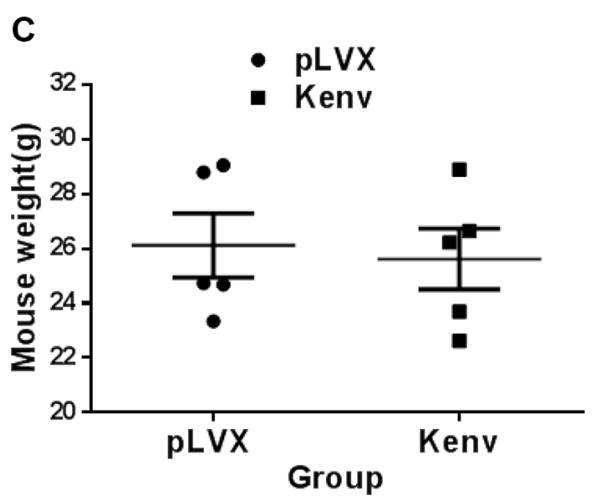

D
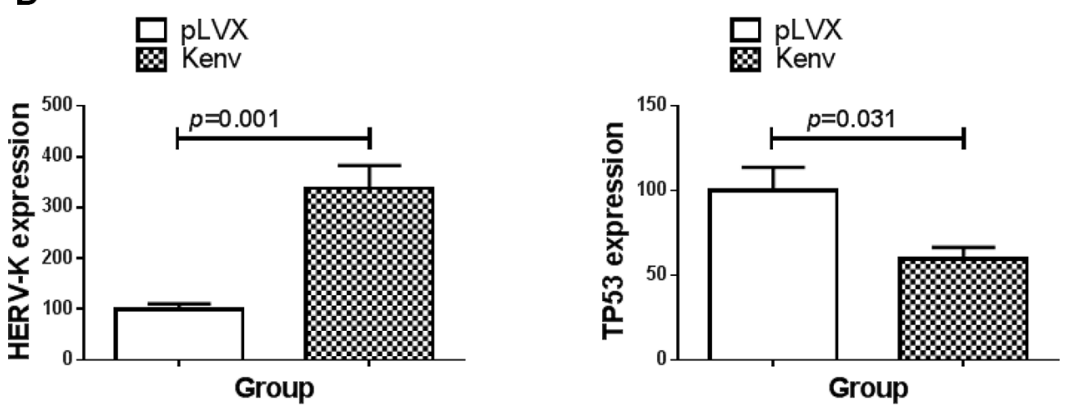

囬 KLnv

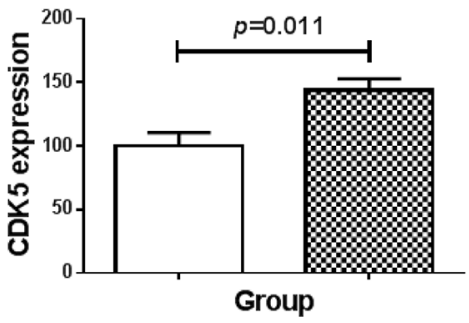

E

pLVX

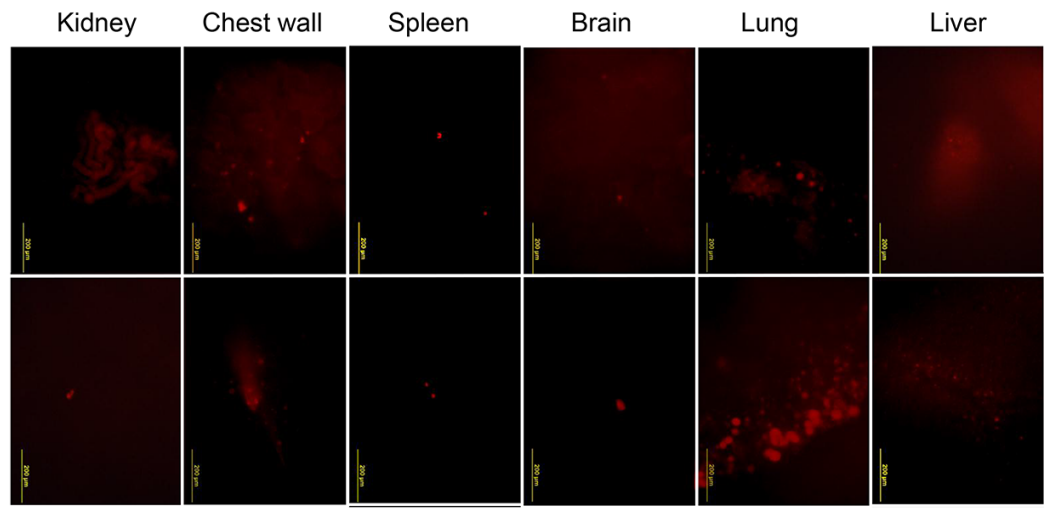

Kenv 


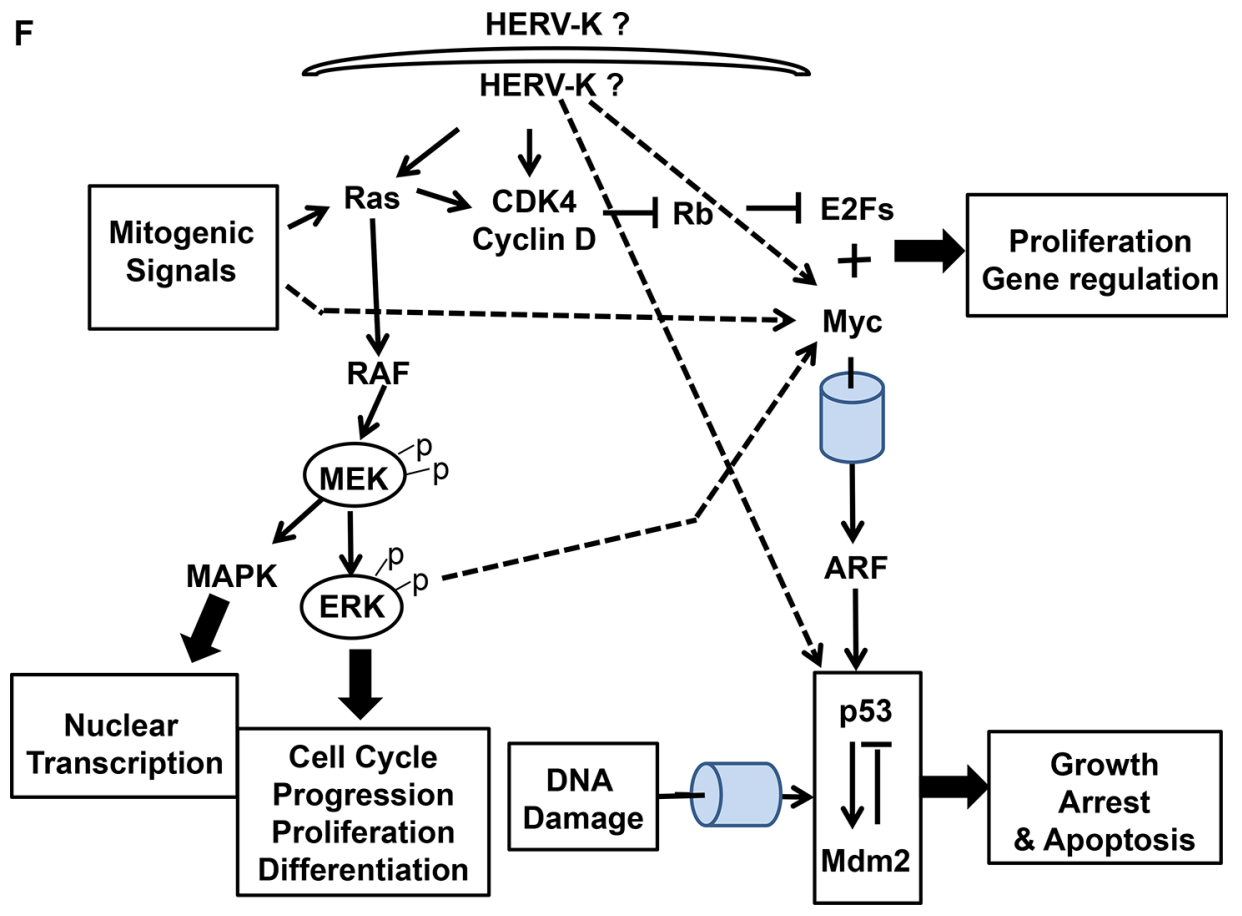

Figure 7: Effect of HERV-K overexpression on tumor growth in mouse xenografts. No significant increase in tumor growth was observed in immunodeficient mice xenografted with MDA-MB-231 cells transduced with Kenv compared with cells transduced with pLVX (vector only) (A). Tumor sizes and weights were not significantly increased in xenografts of cells transduced with Kenv $(p=0.7397)(\mathbf{B})$. A slight but nonsignificant loss in body weight was observed in mice bearing Kenv cells compared with pLVX cells $(p=0.7635)(\mathbf{C})$, and qRT-PCR was employed to determine the expression of HERV-K in MDA-MB-231+Kenv or +pLVX. Significantly increased expression of HERV-K and CDK5 in MDA-MB-231+Kenv cells was observed, compared with MDA-MB-231+pLVX cells (D). There was also significantly reduced expression of p53 in MDA-MB-231+Kenv cells (D). Increased metastasis to lung (red fluorescence) in MDA-MB- 231+Kenv cells was observed (E). A summary of pathways related to HERV-K Env protein is shown $(\mathbf{F})$.

thus appears to be a critical first step in Ras-induced transformation and tumorigenesis of human $\mathrm{BC}$ cells.

The decrease in Ras expression that resulted from HERV-K knockdown with an shRNA was associated with phenotypic changes that resembled the development of EMT. But proteins whose expression changed in HERV-K knockdown cells were not characteristic of EMT. We hypothesize that HERV-K knockdown BC cells may be undergoing a reversion to a non-tumorigenic phenotype, a hypothesis supported by both in vitro and in vivo data.

In this study we investigated aspects of HERV-K expression that promoted BC progression. Significantly decreased migration, invasion, and transformation was documented in $\mathrm{BC}$ cell lines stably transduced with a vector that knocked down expression of the HERV-K env gene. Knockdown of HERV-K in these cells by introduction of an shRNA that blocked its expression also led to decreases in tumor growth and tumor weight, as well as downregulated expression of pERK1/2 and Ras proteins.

Our current study and a previous study using a chimeric antigen receptor antibody demonstrated that expression of HERV-K is related to breast cancer metastasis [8]. Since immunodeficient mice bearing
MDA-MB-231 tumors consistently develop widespread metastases, we decide to evaluate this xenograft model initially, with a focus primarily on metastasis. Our results show that overexpression of HERV-K in this metastatic breast cancer cell line does indeed lead to increased lung metastasis. With respect to tumor growth, we suggest that the aggressive MDA-MB-231 tumors have reached their maximum potential for growth in xenografts, and overexpression of HERV-K does not further promote tumor growth in this model. However, HERV-K overexpression does still stimulate metastasis in this model. In future and ongoing studies we are focusing our xenograft studies on cells that have lower expression of HERV-K, such as conditionally reprogrammed normal breast, immortalized breast, and pre-neoplastic breast cells, to determine whether HERV-K overexpression from a baseline of low expression will promote tumorigenesis in mouse xenograft models of breast cancer.

Although mice inoculated with MDA-MB-231 cells stably transduced with the HERV-K env gene (Kenv) did not show increased tumor weights, there was increased in vitro invasion, migration, and colony formation in soft agar, all of which support a role of HERV-K in tumor 
progression and metastasis. This concept was supported by our in vivo observation of increased metastasis to the lung and brain in mice whose tumors overexpressed HERV-K. Overexpression of CDK5 in breast cancer has been found to correlate with several poor prognostic parameters. It is essential for TGF- $\beta$-induced EMT and breast cancer progression [30].

In conclusion, our data indicate that the expression of HERV-K Env protein is essential for Ras-induced tumorigenesis in $\mathrm{BC}$ cells. We also provide evidence that downregulation of HERV-K expression by shRNA can be used for understanding mechanisms of tumorigenesis of $\mathrm{BC}$, and that HERV-K knockdown may induce reversion of $\mathrm{BC}$ cells to a non-tumorigenic phenotype. HERV-K is thus a novel target for therapeutic intervention of Rasdriven tumors. Our studies have identified an important tumor oncogene involved in $\mathrm{BC}$ progression and have revealed an alternative mechanism by which Ras becomes activated in this disease.

\section{MATERIALS AND METHODS}

\section{Cell culture}

All BC cell lines (MDA-MB-231, Hs578T, MCF-7, SKBR3 and 293TN cells) were purchased from American Type Culture Collection (ATCC; Manassas, VA, USA). MDA-MB-231 (metastatic; 51 year old Caucasian female) and Hs578T (74 year old Caucasian female) are triple negative $\mathrm{BC}$ cell lines. MCF-7 (estrogen receptor positive; 69 year old Caucasian female) and SKBR3 (overexpressing HER2; 43 year old Caucasian female) are $\mathrm{BC}$ cell lines derived from an adenocarcinoma metastatic site. MDA-MB-435.eB1 cells (31 year old Caucasian female: a gift from Dr. Michael Rosenblum) are human BC cells that have been transfected with c-erbB2 oncogene, and express high levels of the trans-membrane glycoprotein p185 c-erbB2. Cells were cultured in RPMI or DMEM (Thermo Scientific, Rockford, IL) with 10\% FBS (Thermo Scientific) and 5\% glutamax (Gibco Life technologies, Grand Island, NY) (complete media). All cell lines were mycoplasma free in our experiments. Cell viability was analyzed before each assay using a trypan blue dye exclusion assay, and was always greater than $96 \%$.

\section{HERV-K env shRNA lentiviral packaging and transduction}

Short hairpin RNAs (shRNAs) targeting the HERV-K env gene (GenBank No. M14123.1) (shRNAenv) and matched scrambled shRNA sequences serving as negative controls (shRNAc) were designed using the Invitrogen RNAi Designer program, and cloned into the pGreenPuro ${ }^{\mathrm{TM}}$ lentiviral expression vector (System Biosciences)(SBI). The shRNA-expressing lentiviral particles were then packaged using pPACKH1 Lentivector Packaging Kit (SBI) following the manufacturer's instructions, and the viral particles were generated in our laboratory. Virus particles were titered using H1299 cells following the manufacturer's instructions. BC cells $\left(1 \times 10^{5}\right)$ were seeded into individual wells of 6-well plates and infected with lentiviral particles carrying shRNAenv or matched shRNAc at a multiplicity of infection (MOI) of 40 .

\section{RT-PCR and qRT-PCR analysis}

RNA was isolated from cells or tumor biopsy specimens $[2,31]$. qRT-PCR was carried out using the TaqMan $^{\circledR}$ One-Step RT-PCR Master Mix Reagents Kit (Life Technologies, Grand Island, NY) to amplify a HERV-K specific sequence, as described previously [3]. Multiple HERV-K gene fragments were amplified by RTPCR using the QIAGEN OneStep RT-PCR Kit (QIAGEN, Valencia, CA): RT-PCR was carried out by reverse transcription for $30 \mathrm{~min}$ at $50^{\circ} \mathrm{C}$, followed by 15 minutes of inactivation at $95^{\circ} \mathrm{C}$, and 35 cycles of 30 seconds at $94^{\circ} \mathrm{C}, 30$ seconds at $55^{\circ} \mathrm{C}$, and 60 seconds at $72^{\circ} \mathrm{C}$ for both types of HERV-K surface (SU) genes.

\section{Immunoblot analysis}

Total protein lysates of cells or tissues were used for immunoblot analysis ( $25 \mu \mathrm{g}$ of protein per lane) as described previously [5, 32]. Anti-HERV-K mAb 6H5 (1 $\mu \mathrm{g} / \mathrm{ml}$ ) generated from our lab $[5,6]$, anti-actin (ACTB) antibodies (1:100 dilution; University of Iowa), phosphop44./p \42 MAP kinase (Erk1/2) (137F5) (Cell Signaling Technology), HIF-1 $\alpha$ (1:1,000 dilution; Santa Cruz), antiRas antibody (1:1,000 dilution; 27H5; Rabbit mAb \#3339; Cell Signaling Technology), and MDM2 (1:1,000 dilution; Sigma-Aldrich) were used as primary antibodies. AntimIgG-680 or anti-rIgG-680 fluorescent antibody (1:5000 dilution; Li-Cor, Lincoln, NE) served as the secondary antibody, as described previously [33, 34], and signal was detected and recorded by the Li-Cor Odyssey imaging system. Protein levels were quantified by Image J software (NIH, Bethesda, MD).

\section{Alamar blue assay for cell viability and cell proliferation}

BC cells were seeded in flat-bottomed 96-well culture plates at a density of $1 \times 10^{4}$ cells/well. After 24 hours, ten microliters of Alamar Blue (AbD Serotec, U.K.) was added to each well and the plates were incubated $37^{\circ} \mathrm{C}$ and fluorescence intensity was measured at different time points using a Victor 1402 multilabel counter (Wallac). The amount of fluorescence was a measure of cell viability.

For cell proliferation assays by cell counting, $1 \times 10^{5}$ cells per well were plated in complete medium 
in a $24-w e l l$ plate and incubated at $37^{\circ} \mathrm{C}$. Cells were then harvested, at different time points and proliferation rates were measured by counting viable cells using the trypan blue dye exclusion method.

\section{Anchorage-independent growth}

Anchorage-independent growth of shRNA transduced cells was tested according to a published method [35]. Colonies were counted after 2 to 3 weeks of incubation and scored by counting the number of colonies greater than $50 \mu \mathrm{m}$ in diameter.

\section{Transwell plate assay}

For migration and invasion assays, 24-well plates with transwell permeable supports (Fisher Scientific, Pittsburgh, PA) were used. Cells were trypsinized, counted and suspended in serum-free medium at a dilution of $2.5 \times 10^{5} / \mathrm{ml}$. $200 \mu \mathrm{l}$ serum-free medium with suspended cells was placed into the upper chamber, which was coated with Matrigel (BD Biosciences, San Jose, CA) for invasion assays or left uncoated for migration assays. $750 \mu \mathrm{l}$ complete medium was placed into the bottom chamber. This assay, as well as time-lapse wound-healing assays (scratch assay), were completed using a standard protocol [36].

\section{In vivo studies}

Female immunodeficient nude or NOD/SCID/ gamma mice, 6- to 8-weeks of age (NCI, Frederick, $\mathrm{MD})$, were inoculated subcutaneously in the flank with $1 \times 10^{6}$ MDA-MB-231, MDA-MB-435.3B1, or SKBR3 cells transduced with shRNAenv or shRNAc to assess tumorigenesis and phenotypes of these cells in vivo. Tumor growth was measured twice per week. Tumors were harvested and weighed, H\&E staining was used to provide histologic evidence of malignancy, and IHC was performed to analyze gene expression. RNAs were isolated from both groups and the expression of HERV-K env RNA was determined by qRT-PCR/RTPCR. Lung tissues were also collected and cultured, and metastatic BC cells in the lung were compared between the two groups.

\section{Immunofluorescence staining and fluorescence-activated cell sorting assay}

Cells were incubated with $6 \mathrm{H} 5 \mathrm{mAb}$ and analyzed by fluorescence microscopy to detect immunofluorescent staining of HERV-K conjugated with Alexa Fluor ${ }^{\circledR} 488$. DAPI (Invitrogen) was used for nuclear staining. For the detection of cytoplasmic Env expression, cells were treated with $0.1 \%$ Triton X-100 (Sigma-Aldrich) as described previously [12]. HERV-K SU protein levels were quantitated using the quantitative indirect immunofluorescence (QIFI) assay, with beads from a QIFIKIT kit (Dako North America, Inc., Carpinteria, CA), by flow cytometry using 6H5-A647 (antibody conjugated to Alexa Fluor dye), as described previously [6]. Propium iodide (PI) staining was performed for cell cycle analysis.

\section{RNA-seq and bioinformatics data analysis}

RNA was isolated from the mouse xenograft tumors of shRNAenv or shRNAc cells. The RNA-seq libraries were prepared with an Illumina TruSeq Stranded Total RNA kit and sequenced using a $2 \times 76$ bases paired end protocol on the Illumina HiSeq 2000 instrument. Each library was sequenced in $1 / 6$ lane, generating about 20-35 million pairs of reads per sample. The reads were mapped to human genome (hg19) by TopHat (V2.0.6). The number of fragments in each known gene from the RefSeq database (downloaded from UCSC Genome Browser on March 09, 2012) was enumerated using htseqcount from HTSeq package (V0.5.3p9). The differential expression was statistically accessed by R/Bioconductor package edgeR (V3.0.8). Genes with FDR $\leq 0.05$ were called significant. All statistical tests were two-sided, and differences between variables with a $P$ value of $<0.05$ were considered statistically significant. The Ingenuity Pathway Analysis (IPA) program was used for downstream analysis of differentially expressed genes. The top 25 upstream regulators, and disease and functions from each paired cell line were used for analysis of the profile of each $\mathrm{BC}$ cell line.

\section{Immunohistochemistry for HERV-K Env expression and phosphorylation profiles of kinases in HERV-K knockdown cells}

IHC was performed on $5 \mu \mathrm{m}$ formalin-fixed, paraffin-embedded tissue sections using standard protocols and a Vectastain ABC Kit (Vector Laboratories, Burlingame, CA), as described previously [5]. A Human Phospho-Kinase Array (ARY003B; R\&D systems) was employed to simultaneously detect the relative site-specific phosphorylation of 43 kinases. Cellular extracts prepared from the MCF-7 cell line transduced with shRNAenv vs. shRNAc were compared and results were evaluated after 30 min exposure.

\section{Construction of vectors expressing HERV-K env or HERV-K env mutant gene}

A full-length HERV-K env sequence from a viral particle isolated from a $\mathrm{BC}$ patient diagnosed with invasive ductal carcinoma was cloned into vector $\mathrm{pLVX}$ DsRed-Monomer-C1 to construct the HERV-K envexpressing vector pLVX-Kenv. Mutations that could 
eliminate the recognition of HERV-K env by shRNAenv but not influence the protein sequence of HERV-K Env were introduced into pLVX-Kenv using a QuikChange ${ }^{\circledR}$ Site-Directed Mutagenesis Kit (Stratagene), to form pLVX-Kmut which could overcome the knockdown effect of shRNAenv if co-transduced with it. The HERV-K env expressing lentiviral particles were then packaged and titered in 293FT cells according to the manufacturer's instructions. The empty vector pLVXDsRed-Monomer-C1 was also packaged to form the control lentiviral particles $(\mathrm{pLVX}) .1 \times 10^{5}$ cells were seeded into individual wells of 6-well plates and infected with different lentiviral particles at a MOI of 40. After two weeks, qRT-PCR and immunoblot were performed to detect HERV-K Env expression.

\section{Statistical analysis}

We used Student's $t$-test to analyze differences between treatment groups in cell culture experiments using GraphPad Prism 6 (GraphPad Software). All statistical tests were two-sided, and differences between variables with a $P$ value of $<0.05$ were considered statistically significant.

\section{ACKNOWLEDGMENTS AND FUNDING}

This work was supported in part by grant BC052782 and BC113114 from the United States Department of Defense, grant 02-2011-104 from the Avon Foundation for Women, and CPRIT Core Facility Support Award RP120348.

\section{CONFLICTS OF INTEREST}

No potential conflicts of interest were disclosed by the authors.

\section{Authors' contributions}

FZ, ML, and YW performed the experiments. KL, YL, and JJS performed the RNA Seq analysis. FWJ and GLJ designed the experiments, performed biostatistical analysis, and wrote the manuscript.

\section{REFERENCES}

1. Li WH, Gu Z, Wang H, Nekrutenko A. Evolutionary analyses of the human genome. Nature. 2001; 409:847-849.

2. Wang-Johanning F, Frost AR, Johanning GL, Khazaeli MB, LoBuglio AF, Shaw DR, Strong TV. Expression of human endogenous retrovirus $\mathrm{k}$ envelope transcripts in human breast cancer. Clin Cancer Res. 2001; $7: 1553-1560$.
3. Wang-Johanning F, Frost AR, Jian B, Epp L, Lu DW, Johanning GL. Quantitation of HERV-K env gene expression and splicing in human breast cancer. Oncogene. 2003; 22:1528-1535.

4. Wang-Johanning F, Li M, Esteva FJ, Hess KR, Yin B, Rycaj K, Plummer JB, Garza JG, Ambs S, Johanning GL. Human endogenous retrovirus type $\mathrm{K}$ antibodies and mRNA as serum biomarkers of early-stage breast cancer. Int J Cancer. 2014; 134:587-595.

5. Wang-Johanning F, Radvanyi L, Rycaj K, Plummer JB, Yan P, Sastry KJ, Piyathilake CJ, Hunt KK, Johanning GL. Human endogenous retrovirus $\mathrm{K}$ triggers an antigen-specific immune response in breast cancer patients. Cancer Res. 2008; 68:5869-5877.

6. Wang-Johanning F, Rycaj K, Plummer JB, Li M, Yin B, Frerich K, Garza JG, Shen J, Lin K, Yan P, Glynn SA, Dorsey TH, Hunt KK, et al. Immunotherapeutic potential of anti-human endogenous retrovirus- $K$ envelope protein antibodies in targeting breast tumors. J Natl Cancer Inst. 2012; 104:189-210.

7. Zhao J, Rycaj K, Geng S, Li M, Plummer JB, Yin B, Liu H, Xu X, Zhang Y, Yan Y, Glynn SA, Dorsey TH, Ambs S, et al. Expression of Human Endogenous Retrovirus Type K Envelope Protein is a Novel Candidate Prognostic Marker for Human Breast Cancer. Genes Cancer. 2011; 2:914-922. doi: 10.1177/1947601911431841.

8. Zhou F, Krishnamurthy J, Wei Y, Li M, Hunt K, Johanning GL, Cooper LJ, Wang-Johanning F. Chimeric antigen receptor $\mathrm{T}$ cells targeting HERV-K inhibit breast cancer and its metastasis through downregulation of Ras. Oncoimmunology. 2015; 4:e1047582.

9. Krishnamurthy J, Rabinovich BA, Mi T, Switzer KC, Olivares S, Maiti SN, Plummer JB, Singh $\mathrm{H}$, Kumaresan PR, Huls HM, Wang-Johanning F, Cooper LJ. Genetic Engineering of T Cells to Target HERV-K, an Ancient Retrovirus on Melanoma. Clin Cancer Res. 2015; 21:3241-3251.

10. Rycaj K, Plummer JB, Yin B, Li M, Garza J, Radvanyi L, Ramondetta LM, Lin K, Johanning GL, Tang DG, WangJohanning F. Cytotoxicity of human endogenous retrovirus K-specific T cells toward autologous ovarian cancer cells. Clin Cancer Res. 2015; 21:471-483.

11. Lam JK, Chow MY, Zhang Y, Leung SW. siRNA Versus miRNA as Therapeutics for Gene Silencing. Mol Ther Nucleic Acids. 2015; 4:e252.

12. Wang-Johanning F, Liu J, Rycaj K, Huang M, Tsai K, Rosen DG, Chen DT, Lu DW, Barnhart KF, Johanning GL. Expression of multiple human endogenous retrovirus surface envelope proteins in ovarian cancer. Int J Cancer. 2007; 120:81-90.

13. Masuda $H$, Zhang D, Bartholomeusz C, Doihara $H$, Hortobagyi GN, Ueno NT. Role of epidermal growth factor receptor in breast cancer. Breast Cancer Res Treat. 2012; 136:331-345. 
14. Kendellen MF, Bradford JW, Lawrence CL, Clark KS, Baldwin AS. Canonical and non-canonical NF-kappaB signaling promotes breast cancer tumor-initiating cells. Oncogene. 2014; 33:1297-1305.

15. Bos R, van Diest PJ, van der Groep P, Shvarts A, Greijer $\mathrm{AE}$ and van der Wall E. Expression of hypoxia-inducible factor-1alpha and cell cycle proteins in invasive breast cancer are estrogen receptor related. Breast Cancer Res. 2004; 6:R450-459.

16. Li S, Wei Q, Li Q, Zhang B, Xiao Q. Down-regulating HIF1alpha by lentivirus-mediated shRNA for therapy of triple negative breast cancer. Cancer Biol Ther. 2015; 16:866-875.

17. Chiappinelli KB, Strissel PL, Desrichard A, Li H, Henke C, Akman B, Hein A, Rote NS, Cope LM, Snyder A, Makarov V, Buhu S, Slamon DJ, et al. Inhibiting DNA Methylation Causes an Interferon Response in Cancer via dsRNA Including Endogenous Retroviruses. Cell. 2015; 162:974-986.

18. Roulois D, Loo Yau H, Singhania R, Wang Y, Danesh A, Shen SY, Han H, Liang G, Jones PA, Pugh TJ, O'Brien C, De Carvalho DD. DNA-Demethylating Agents Target Colorectal Cancer Cells by Inducing Viral Mimicry by Endogenous Transcripts. Cell. 2015; 162:961-973.

19. Rooney MS, Shukla SA, Wu CJ, Getz G, Hacohen N. Molecular and genetic properties of tumors associated with local immune cytolytic activity. Cell. 2015; 160:48-61.

20. Golan M, Hizi A, Resau JH, Yaal-Hahoshen N, Reichman H, Keydar I, Tsarfaty I. Human endogenous retrovirus (HERV-K) reverse transcriptase as a breast cancer prognostic marker. Neoplasia. 2008; 10:521-533.

21. Gulati AP, Yang YM, Harter D, Mukhopadhyay A, Aggarwal BB, Benzil DL, Whysner J, Albino AP, Murali R, JhanwarUniyal M. Mutant human tumor suppressor p53 modulates the activation of mitogen-activated protein kinase and nuclear factor-kappaB, but not c-Jun N-terminal kinase and activated protein-1. Mol Carcinog. 2006; 45:26-37.

22. Huang G, Li Z, Wan X, Wang Y, Dong J. Human endogenous retroviral $\mathrm{K}$ element encodes fusogenic activity in melanoma cells. J Carcinog. 2013; 12:5.

23. Castellano E, Downward J. RAS Interaction with PI3K: More Than Just Another Effector Pathway. Genes Cancer. 2011; 2:261-274. doi: 10.1177/1947601911408079.

24. Wang J, Yuan Y, Zhou Y, Guo L, Zhang L, Kuai X, Deng B, Pan Z, Li D, He F. Protein interaction data set highlighted with human Ras-MAPK/PI3K signaling pathways. J Proteome Res. 2008; 7:3879-3889.

25. Man JH, Liang B, Gu YX, Zhou T, Li AL, Li T, Jin BF, Bai B, Zhang HY, Zhang WN, Li WH, Gong WL, Li HY, et al. Gankyrin plays an essential role in Ras-induced tumorigenesis through regulation of the RhoA/ROCK pathway in mammalian cells. J Clin Invest. 2010; 120:2829-2841.
26. McLaughlin SK, Olsen SN, Dake B, De Raedt T, Lim E, Bronson RT, Beroukhim R, Polyak K, Brown M, Kuperwasser C, Cichowski K. The RasGAP gene, RASAL2, is a tumor and metastasis suppressor. Cancer cell. 2013; 24:365-378.

27. McCubrey JA, Steelman LS, Chappell WH, Abrams SL, Wong EW, Chang F, Lehmann B, Terrian DM, Milella M, Tafuri A, Stivala F, Libra M, Basecke J, et al. Roles of the Raf/MEK/ERK pathway in cell growth, malignant transformation and drug resistance. Biochim Biophys Acta. 2007; 1773:1263-1284.

28. Clark GJ, Kinch MS, Gilmer TM, Burridge K, Der CJ. Overexpression of the Ras-related TC21/R-Ras2 protein may contribute to the development of human breast cancers. Oncogene. 1996; 12:169-176.

29. Hoadley KA, Weigman VJ, Fan C, Sawyer LR, He X, Troester MA, Sartor CI, Rieger-House T, Bernard PS, Carey LA, Perou CM. EGFR associated expression profiles vary with breast tumor subtype. BMC genomics. 2007; $8: 258$.

30. Liang Q, Li L, Zhang J, Lei Y, Wang L, Liu DX, Feng J, Hou P, Yao R, Zhang Y, Huang B, Lu J. CDK5 is essential for TGF-beta1-induced epithelial-mesenchymal transition and breast cancer progression. Sci Rep. 2013; 3:2932.

31. Wang-Johanning F. Quantitation of HERV-K env gene expression and splicing in human breast cancer. Oncogene. $2003 ; 22: 1528-1535$.

32. Wang-Johanning F, Gillespie GY, Grim J, Rancourt C, Alvarez RD, Siegal GP, Curiel DT. Intracellular expression of a single-chain antibody directed against human papillomavirus type 16 E7 oncoprotein achieves targeted antineoplastic effects. Cancer Res. 1998; 58:1893-1900.

33. Pan Y, Zhou F, Zhang R, Claret FX. Stat3 inhibitor Stattic exhibits potent antitumor activity and induces chemo- and radio-sensitivity in nasopharyngeal carcinoma. PLoS One. 2013; 8:e54565.

34. Pan Y, Zhang Q, Atsaves V, Yang H, Claret FX. Suppression of Jab1/CSN5 induces radio- and chemosensitivity in nasopharyngeal carcinoma through changes to the DNA damage and repair pathways. Oncogene. 2013; 32:2756-2766.

35. Ben El Kadhi K, Roubinet C, Solinet S, Emery G, Carreno S. The inositol 5-phosphatase dOCRL controls $\mathrm{PI}(4,5) \mathrm{P} 2$ homeostasis and is necessary for cytokinesis. Curr Biol. 2011; 21:1074-1079.

36. Schaeffer D, Somarelli JA, Hanna G, Palmer GM, GarciaBlanco MA. Cellular migration and invasion uncoupled: increased migration is not an inexorable consequence of epithelial-to-mesenchymal transition. Mol Cell Biol. 2014; 34:3486-3499. 